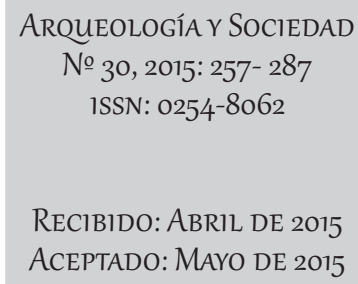

RECIBIDO: ABRIL DE 2015

ACEPTADO: MAYO DE 2015

\title{
LA OCUPACIÓN HUARPA EN TAMBO, LA MAR
}

\author{
ISMAEL PÉREz CALDERón \\ UnIVERSIDAD NACIONAL SAN CRISTOBAL DE HUAMANGA \\ zperezun_sch@hotmail.com \\ Nelson Carrera Aquino \\ UNIVERSIDAD NACIONAL SAN CRISTOBAL DE HUAMANGA \\ nelson_wend@hotmail.com
}

\section{RESUMEN}

Presentamos información de un conjunto de asentamientos arqueológicos existentes en la parte superior del curso del río Torobamba, afluente principal del río Pampas, zona nororiental de Ayacucho. Los sitios se ubican entre 2800 y 4250 en la provincia de la Mar, o flanco oriental de la cordillera del Razuwillcca, que se conecta con el Apurímac, espacio no explorado desde por lo menos hace 3 décadas, a raíz de los sucesos de violencia ocurridos en Uchuracay, la distribución de asentamientos demuestra que no solo fue zona de ruta de antiguos pobladores que desplazaban hacia la selva sino que fue territorio con una densa población, de manera especial durante las épocas Huarpa y Huari (200 a.C.-1200 d.C), cuyos estados debieron de controlar el aprovechamiento de recursos existentes, caso de minerales, productos agrícolas y de ganadería. Complementamos la información con el registro etnográfico y datos de colecciones particulares.

Palabras Clave: Huarpa, arqueología, Ayacucho, Tambo.

\section{ABSTRACT}

We present a set of information existing in the upper course of Torobamba river, the main tributary of the Pampas river, northeastern Ayacucho archaeological sites. The sites are located between 2800 and 4250 in the province of the Sea or eastern flank of the Cordillera del Razuwillcca, which connects with the Apurimac, unexplored space for at least 3 decades, following the violent events that occurred in Uchuracay, the distribution of settlements shows that it was not just old path area residents who moved into the jungle but was a territory with a dense population, especially during Huarpa and Huari (200 AD-1200 AD) eras, whose states should control the use of existing resources, if minerals, agricultural products and livestock. We complement the ethnographic record information and data from private collections.

KeYwords: Huarpa, arqueología, Ayacucho, Tambo. 


\section{INTRODUCCIÓN}

Tambo es el distrito con mayor población, basta mirar como en los últimos 20 años su población ha crecido aceleradamente con diferentes asentamientos localizados en la periferia del pueblo principal, lo cual se debe quizá a la fertilidad de su tierra, desde las alturas donde se originan las lagunas, manantiales y quebradas que forman el curso superior del río Torobamba hasta la parte baja donde existe riego permanente convirtiéndola en una zona eminentemente agrícola con una variedad de papa nativa, junto a lo cual se cultiva quinua, olluco, oca y mashua, así como el maíz, calabazas y frutales. Es la ruta del comercio por donde diariamente se desplaza la población de Ayacucho hacia la selva, conforme lo fue en el pasado desde las ciudades de Ñawimpuquio y Wari, con caminos que unían a diferentes centros de acopio o centros administrativos de las épocas Huarpa y Wari establecidos en los valles de Tambo y San Miguel.

De acuerdo con datos recabados del PETT y talleres de diagnóstico local, Tambo, cuenta con 44 comunidades campesinas y 6 anexos, incluyendo a las comunidades de Estera y Villa, y otras comunidades ubicadas al sur del distrito de Tambo que a pesar de pertenecer territorialmente al distrito de San Miguel se identifican con el distrito de Tambo, otro caso es la comunidad de Uchuracay, ubicado al norte del distrito de Tambo que pertenece políticamente a la provincia de Huanta, pero administrativamente y por tradición a Tambo, lo que implica que el área de Tambo están unidos a una misma unidad geográfica.

En el área objeto de la presente investigación, siguiendo la propuesta de Pulgar (1996) encontramos tres regiones naturales: Quechua, determinado por el pueblo de Tambo, quebradas y laderas que la rodean; Suni, constituido por laderas empinadas aprovechadas en parte por la agricultura que llega hasta zonas próximas a las lagunas y la Jalca, constituida por el entorno de las lagunas abras, colinas y salientes de la cordillera del Razuwillcca vinculadas con el culto mágico religioso de los antiguos pobladores. Estas tres regiones están dotadas de una rica flora y fauna de plantas, animales y recursos minerales que fueron aprovechados desde tiempos prehistóricos, donde en el modo de vida del hombre actual siguen vigentes costumbres tradicionales como el ayni, minka, uso de Chaquitaclla, organización comunal, autoridades andinas (varayoc), intercambio o trueque, y el sistema de los pagos que deben representar a las diferentes agrupaciones sociales o poblaciones que existieron desde el pasado preincaico.

\section{Geología y GEOMORFología}

La cuenca superior del río Torobamba donde se inicia el área de estudio en las lagunas de Toctococha, Uscococha y Yanacocha, están rodeadas de roca intrusiva del grupo Batolito Permo-Triásico con el tipo de roca Granito de San Miguel que forma laderas de pendiente empinada tal como se puede apreciar en los cerros Balcón y Millpoc. Petrográficamente, la roca es de naturaleza sienogranítica, de textura holocristalina, granular hipiomórfica, gruesa, de color rosado intenso; con minerales esenciales: feldespato potásico principalmente, cuarzo plagioclasas, biotitas y anfíboles estos últimos en cantidades menores, mientras que los feldespatos están relativamente alternados a arcillas, sericia y cloritas. El Granito de San Miguel intruye a los grupos Copacabana y Mitu. Estratigráficamente entre el Permiano Superior de la Era Paleozoica y el Triásico Inferior de la Era Mesozoica. Las rocas del grupo Mitu resaltan en las laderas del cerro Huanchuy al sur de Tambo. Pero lo que más predomina en los cauces de las lagunas, quebradas y ríos que forman el Torobamba son depósitos aluviales del Cuaternario, era Cenozoica que agrupan a diferentes depósitos, tanto fluviales como aluviales, los cuales se caracterizan por componerse de gravas, arenas, limos y arcillas dispuestos en proporciones diversas según el lugar donde se encuentran. 


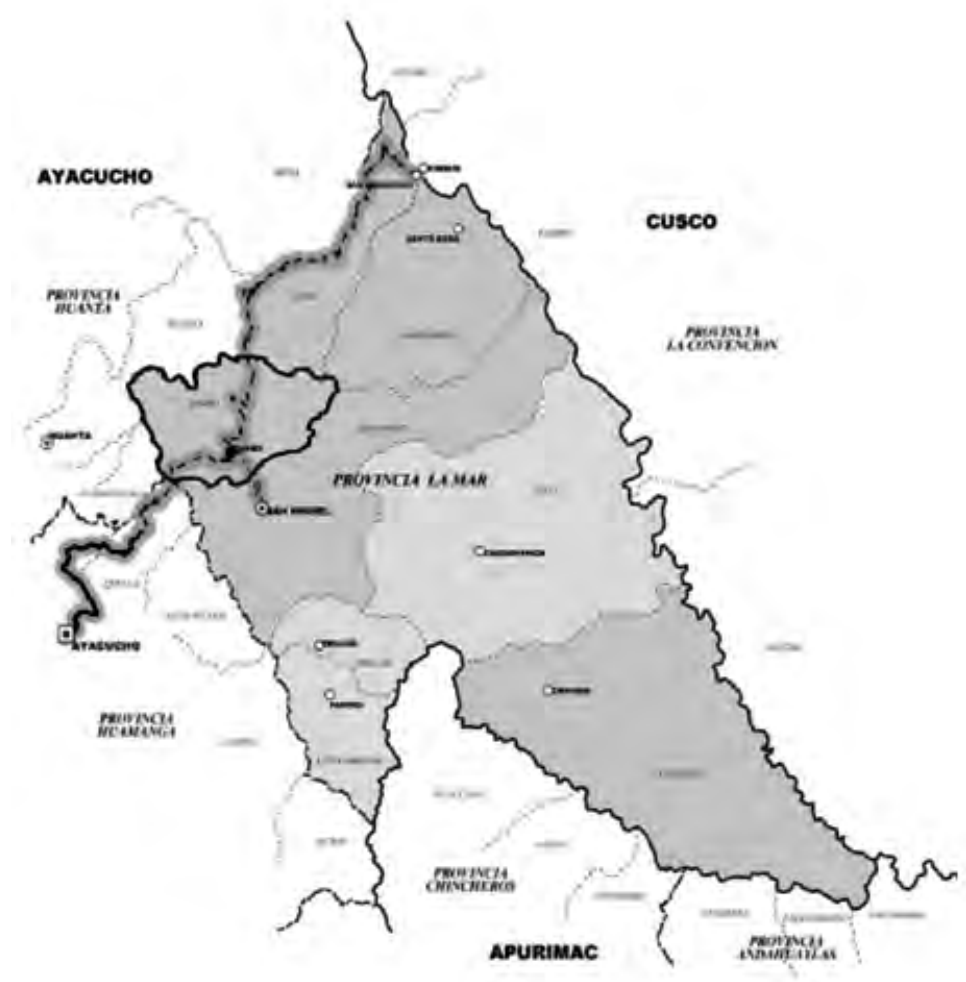

Mapa de ubicación del área de estudio en la provincia de la Mar, Ayacucho

Al oeste de Tambo en la microcuenca de la quebrada Yanamito y Cochapampa, predomina depósitos Glaciofluviales, cuyos sedimentos están compuestos por arenas, gravas, limos y arcillas relacionados íntimamente a antiguas zonas glaciales, mientras que entre los depósitos fluviales que rodean al cerro Marca y laderas sur del pueblo de Tambo destacan afloramientos rocosos de la Formación Tambo que pertenecen al cretáceo Superior (Era Mesozoica) y el Paleógeno (era Cenozoica). Consiste en una secuencia clástica rojiza que se distingue por aparecer siempre formando terrenos bastante suaves, conspicuamente contrastantes con las generadas por las unidades adyacentes. Entre sus principales rasgos resaltan la relativamente importante cobertura de suelo y los numerosos deslizamientos que sobre ella ocurren. En este sentido sus afloramientos constituyen los lugares de asentamiento de poblados y zonas agrícolas (López et al 1996:70).

En la geomorfología el rasgo más destacado es sin duda la cordillera de Razuwilca, con cadenas de cerros y picos de altas pendientes que alcanzan altitudes que oscilan entre los 4,200 a 4,954, con muchas lagunas donde se dividen las aguas que drenan a las cuencas del Mantaro y Apurímac a través de los ríos Huarpa y Pampas, donde la erosión glaciar y fluvioglaciar ha afectado seriamente el terreno dando lugar al típico modelado glaciar, de valles en "U", de circos glaciares con presencia de depósitos morrénicos, formados junto a las lagunas y en la laderas que constituyen las pendientes de los valles como es el caso del valle de Tambo y San Miguel donde resalta las pendientes abruptas de los cerros Marcas y Chincho con altitudes que varían de 2600 a 3,400,caracterizadas por constituir una sucesión morfológica de continuas cuestas buzantes en términos generales hacia el sureste. Esta 
ladera está disectada casi exclusivamente por pequeñas quebradas que surcan transversalmente. Otra de las formas morfológicas corresponde a la depresión que altera el carácter abrupto de la cordillera en las localidades de Mitipampa, Pucajasa, Tambo y Millpo con proyección hacia San Miguel, caracterizada por presentar una topografía moderada parcialmente plana con pendientes medianas, con desniveles que varían entre 2750 y 3400m cuyo relieve aparece disectado por una variedad de quebradas que mantienen cierto carácter agreste. Las lomas y explanadas son otras de las características del relieve que integran el paisaje morfológico de Tambo.

\section{ANTECEDENTES}

Uno de los pioneros en estudios arqueológicos en la ceja de selva en Ayacucho, es Duccio Bonavia quien entre setiembre y octubre de 1963 encabezó la Primera Expedición Científica de Huamanga, explora la parte baja de Pacobamba, distrito de Sacharaccay, provincia de la Mar, registra diferentes cerros con estructuras arqueológicas entre los que destacan Caballoyuq, Matukalli y Raqaraqay, con cerca de 400 recintos de planta circular dispuestos en su mayor proporción a lo largo y ancho del primero que se conecta con Pacos. Bonavia (1964), describe que se trataría de sitios de la época tardía, asociados a un camino que se introduce a Viscatan en la selva del Apurímac, razón por la que Medardo Purizaga, en un interesante trabajo sobre el Estado regional en Ayacucho, al hablar sobre el área geográfica del grupo cultural del Intermedio Tardío en Ayacucho (1200-1470), que formaba parte de la Confederación Chanca, señala que limitaba al NO con los Huancas del Mantaro, al sur con los Rucanas, al SE con los Soras y al este con los Chankas de Andahuaylas, hace especial mención de la posible cultura Arqalla ubicada en las alturas de Huamanga, la cual se difundió desde Caballoyuq, en la ceja de selva de Huanta, hasta Sarhua en el alto Pampas recomendando profundizar las investigaciones con excavaciones en estas área geográfica para comprobar la generalización de la cerámica y arquitectura Arjalla (Purizaga 1972: 10).

Posteriormente, Duccio Bonavia, incide la filiación de los sitios explorados en la ceja de selva de La Mar, e indica que en el área de transición entre la puna y ceja de selva o en la ceja de selva misma de la sierra central conocemos hasta la fecha los siguientes núcleos antiguos de población: Caballoyuq, Matukalli, Raqaraqay, Picopampa, Millaqpata y un sitio anónimo. Los centros de puna son Condoruchko, Uchuihuamanga, Rupaipata y AqoTambo; se debe recalcar sin embargo que ellos están en el área limítrofe con la anterior y exactamente en la ruta de acceso a la ceja de selva. Como se verá más adelante, proponemos que a pesar de su diferente ubicación, estas villas forman parte de un mismo complejo desde el punto de vista cronológico, todos estos núcleos de población pertenecen al Horizonte Tardío, última época de la Cultura andina, ya que la cerámica encontrada en superficie y en las excavaciones corresponde a los tipos Arjalla, Pataraqay y Caballoyuq (Bonavia 1972: 94 - 96).

A fines de la década del sesenta, dos importantes trabajos de investigación arqueológica se desarrollaron en San Miguel, entre enero y marzo que abarcó hasta el valle de Tambo por Carrillo (1969, 1976), quien da cuenta de una densa ocupación cultural con asentamientos establecidos en las cimas, laderas, planicies y partes bajas próximos al cauce del río principal y de algunas quebradas tributarias, consistentes en centros poblados, chullpas, caminos, cuevas y montículos con cerámica y artefactos líticos de superficie atribuidos a la épocas Formativa, Huarpa, Wari, Chanka e Inka, con presencia de los tipos de cerámica Caja, Warpa Negro sobre Blanco, Warpa Tricolor, Warpa Ante, Okros, Totora, Acuchimay, Wari, Huamanga, etc.; es decir toda una secuencia de ocupación cultural, destacando el sitio de Inkaraqay o Jargampata, excavado a mediados de 1969 por William Isbell, quien la define como parte de un pueblo rural o de un probable centro administrativo Wari (Isbell 1970,1972), aso- 
ahora sabemos que está rodeado de asentamientos Huarpa como daremos a conocer más adelante y como el mismo ilustra en una de sus figuras (Isbell 1970, 1977: fig. 42: A, B1 y B2). Al referirse a las culturas intermedias (200 a.C. 600 d.C), menciona que a este complejo ayacuchano, representativo de la época, se le denomina Huarpa, y parece estar conformado por una mezcla de lo indígena del Horizonte Temprano con las nuevas importaciones artísticas, principalmente en Higueras, en Huánuco. Motivos complejos como los de Rancha y Tunasniyoc, proporcionaron por su lado las bases pre-Huarpa a partir de los cuales pudo haberse desarrollado. Cerámica de la nueva tradición se encuentra en el valle de Ayacucho y alrededores, incluyendo en esta, la zona del Mantaro, Huancavelica y áreas inmediatamente al este de Ayacucho (Isbell 1972:47-48), es posible que William Isbell cuando habla de áreas del lado este de Ayacucho se refiera a los valles de Tambo y San Miguel.

Benavides (1976), visita las partes altas del distrito de Tambo registrando el cerro de Quintu Urqu con presencia de chullpas y materiales en cerámica y líticos, donde afirma que hay evidencias de gran cantidad de muros y la cerámica de poca cantidad, con presencia de chullpas y restos de muros. Los muros y chullpas registrados por Mario Benavides corresponde solamente a un sector, ubicado en las alturas del cerro Quintu Urqu que queda en la margen izquierda del río Torobamba. De igual forma, registró los sitios arqueológicos de Ñaupallaqta, Viscachayuq, Ankukichka, San Cristóbal, Acco, Markapata, Pinchu Qasa, Yupin, San Melchor, Piki Muyu, Witu, Tukuwillka, Uqichachayuq Era o Puca Kichka, Masinga, Ayamachay, Waqachina, Suyuqasa, Patakancha, Pata Corral, Intiwatana; en la actualidad solo se conservan 3 de estos sitios arqueológicos.

Lecoq $(2007,2008)$ realiza exploraciones en la comprensión de Chungui, La Mar, donde tiene la suerte de localizar un conjunto de sitios tardíos de filiación Chanka pero con cerámica incisa que demuestra ocupación desde el periodo Formativo. En esta misma zona Añanca y Canchari (2009), reconocen y registran 21 estructuras arqueológicas entre abrigos, poblados, caminos, cámaras funerarias, terrazas y fortificaciones pertenecientes a la época precerámica pero fundamentalmente a las épocas Wari, Chancka e Inka.

En 2008 Hernán Carrillo como resultado de las excavaciones de rescate en los sitio 36 -01 y 36 -03, ubicados en el antiguo Derecho de Vía y la actual variante KP 36 del gaseoducto de PERÚ LNG., informa que la zona se caracteriza por la existencia de diversos restos arqueológicos expuestos en diferentes estados de conservación y grados de complejidad, que corresponderían desde la época Huarpa hasta el periodo Colonial, con componentes que incluyen pequeños conjuntos residenciales, entierros, posibles estructuras ceremoniales, caminos, senderos, terrazas agrícolas de varios tipos y tamaños, y áreas niveladas artificialmente que en mayor porcentaje parecen corresponder a los periodos Huarpa y Chanka, cuyos componentes como es típico en muchos conjuntos arqueológicos, están densamente distribuidos en áreas en donde la pendiente natural es más regular y suave como el caso de la ladera suroriental del cerro Corpas.

Valdez (2009), informa de la presencia de la cultura Warpa en la cuenca del río Torobamba en San Miguel, La Mar, con excavaciones realizadas en los sitios Corpas 4 y 3, en las que destaca un conjunto de andenerías y el descubrimiento de una estructura en "D" asociados con entierros Warpa como parte de los trabajos ejecutados por Perú LNG. Ernesto Valdéz prospecta las alturas que rodean al valle de San Miguel e identifica tres sitios arqueológicos: Allkuwillka, Bañico y Muyu Urqu, todos con restos de recintos circulares en la parte superior de los cerros asociados a cerámica que le atribuye a la cultura Chanka, y en la divisoria de las aguas que drenan a los ríos Huarpa y Torobamba, alturas de las provincias de Huamanga, Huanta y la Mar, documenta los ushnos de Bañico, Inkap Tiyanan y el sitio y ushno de Inka Perqa. Por su parte Torre (2009), explora las alturas de Tambo y Huanta, entre Uchuracay e Iquicha, sobre los $4000 \mathrm{msnm}$., registrando varios sitios atribuidos a la cultura Chankas. 
Aquino (2012), con asesoría de Ismael Pérez, registró 38 sitios arqueológicos, cuyo aporte se basa en la determinación de dos asentamientos del periodo Formativo en las quebradas de Puñosjasa, Yanamitu, Ñaupallaqta y Pampa Hermosa del periodo Huarpa reocupados en la época Wari. Por otro lado Gonzales (2014), es quién se encargó del análisis de la cerámica procedente de Pampa Hermosa, lo que confirma la ocupación Huarpa seguida de Wari, en un sitio que controla la conexión de las partes altas y bajas del valle de Torobamba.

Gagliardi (2013), menciona que en agosto de 2008 hicieron recorridos por el complejo arqueológico de cerro Corpas en la margen izquierda del río Torobamba altura de Patibamba donde cronológicamente, y de acuerdo a los materiales de cerámica recogidos en el sitio. Cerro Corpas se enmarcaría en el período Intermedio Temprano y específicamente bajo filiación Huarpa, siendo los portadores de este estilo de cerámica sus primeros ocupantes o los que han dejado su mayor presencia, y en la descripción del lugar indica, el sistema de abastecimiento de agua,, el área de ocupación habitacional con una estructura en "D" (registrado por Valdez 2009); las vías de comunicación y los anfiteatros designados arbitrariamente como A,B,C y D integrantes de un complejo sistema agrícola.

Finalmente entre otros trabajos realizados en la Mar y alrededores, cabe hacer mención a Raymond Escott (1971) que registró varios sitios en Sivia, Simariba, Kimbiri, Santa Rosa y Lusiana proponiendo que en el pasado prehispánico existió una fluida comunicación e intercambio entre pueblos del bajo Apurímac y las altas montañas o valles interandinos. Castilla (2001), reconoce varios sitios arqueológicos en los distritos de Tambo y Chilcas, en el primero registra a Naupallaqta y Qintuyupanqa, Witku Urqu en la margen izquierda y Punkurumi, en la margen derecha de río Torobamba, concluyendo que la actividad económica es muy fundamental, al igual que la agricultura y el pastoreo, complementado con el intercambio comercial con la ceja de la selva. Córdova (2007) y Cavalcanti (2014) exploran el sitio de Cedrocucho.

\section{DisTRIBUCIÓN ESPACIAL DE RESTOS Y ASENTAMIENTOS}

\section{Chorroqasa sur (T1)}

Camino prehispánico, el tramo observado tiene cerca de $2 \mathrm{~km}$ de largo por $2 \mathrm{~m}$ de ancho, se ubica junto a la carretera Ayacucho Tambo, altura de la laguna Toctococha, el lado sur del camino se proyecta a la ciudad de Huari, pasando por la quebrada Pallca, mientras que el lado opuesto sigue la quebrada Lluncuna en dirección a Huamanguilla. El camino bordea la laguna Toctococha y se pierde en la quebrada Puñosjasa, volviendo a salir en dos ramales uno con dirección al nevado de Razuwillca pasando por la comunidad de Paria, el otro va a Tambo conectándose con asentamientos cercanos a las quebradas Puñosjasa, Yanamitu y Huito. En la actualidad sigue siendo utilizado por los pastores pero por su contacto con los asentamientos sospechamos una filiación cultural de la época Formativa reutilizada por los Huarpas y Huaris.

\section{Pampa Qasa (T2)}

Estructuras circulares, rectangulares y alineamientos de piedras, dispuestos en una extensión aproximada de 2 has, cortadas por la carretera Ayacucho-Tambo, en las faldas de los cerros Apacheta y Chorrojasa. Existen recintos delimitados por muros de doble hilada que parecen corresponder a la cimentación de antiguas chozas o viviendas de pastores-agricultores, algunas están al interior de grandes corralones de forma circular que miden hasta $30 \mathrm{~m}$ de diámetro, y otras al exterior, algo se- 


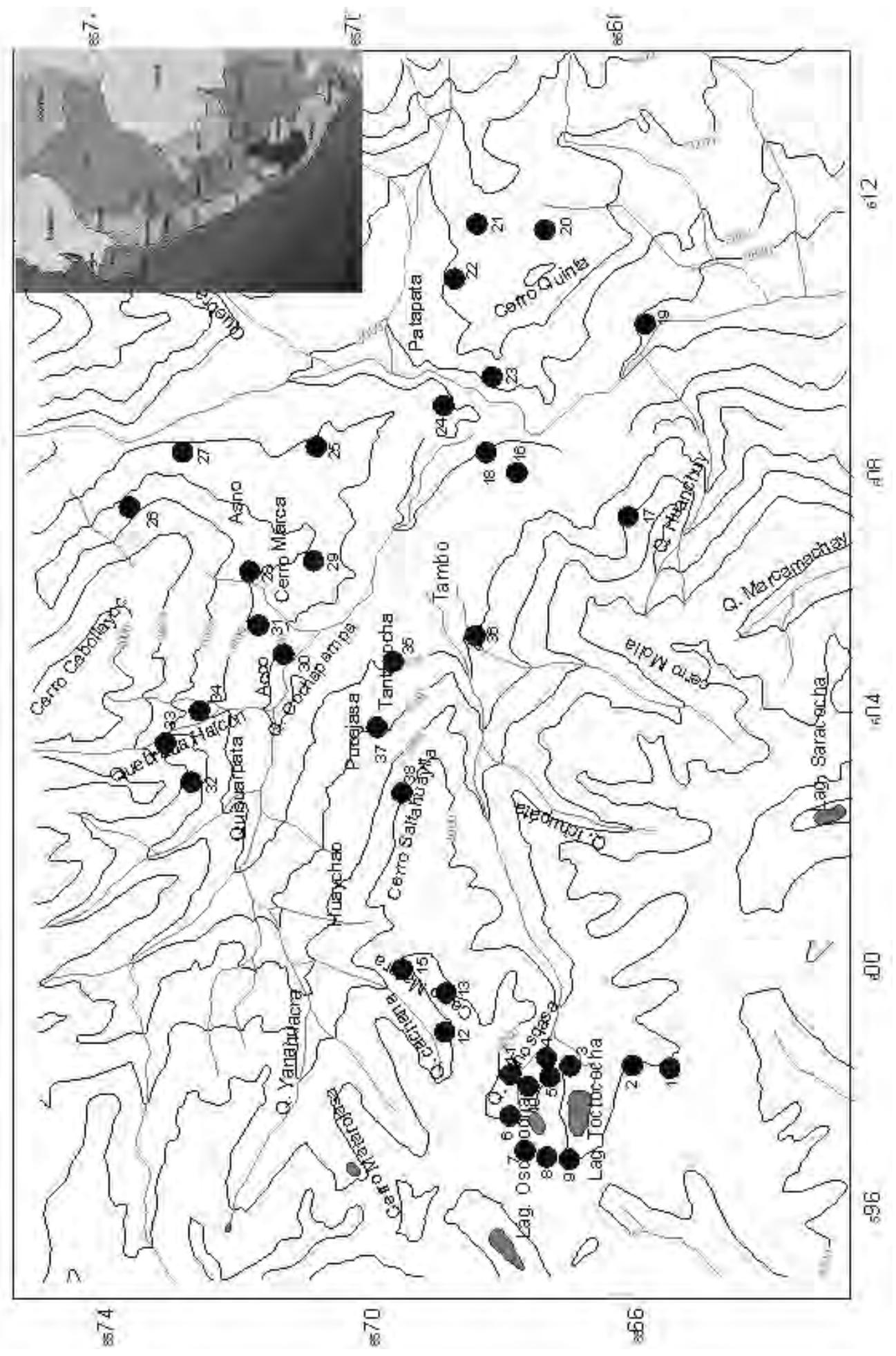


mejante a las casa de pastores actuales en las punas de los Andes centrales. La superficie tiene escasos fragmentos de cerámica erosionados por la humedad, pero los bordes y la decoración incisa sugiere que pertenecen al Formativo Inferior o Cerámico Inicial.

\section{Toctococha A (T3)}

Aldea de pastores-agricultores localizada junto al borde de la laguna Toctoqocha y al lado sur del nacimiento de un riachuelo que baja a Tambo. Consiste en por lo menos 3 agrupaciones de recintos circulares de 3 a $5 \mathrm{~m}$ de diámetro dispuestas alrededor de patios o corredores, adyacentes corralones para crianza y reproducción de camélidos. Los muros de los recintos habitacionales hechas de piedras canteadas dispuestas en dos filas formando un espacio vacío a manera de canaleta donde debió existir una pared de quincha con techo de ichu, asegu-

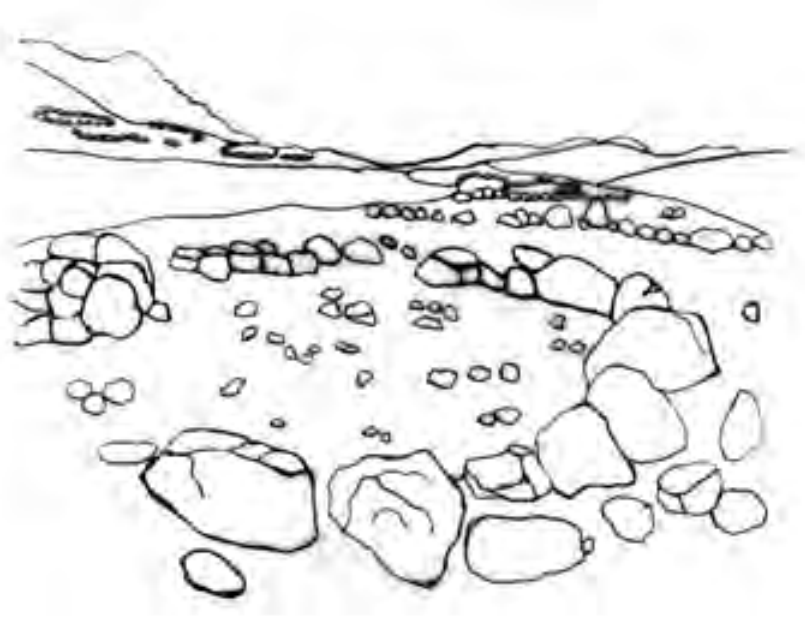
rada con piedras pequeñas. Asociado a la superficie se encontró una punta de proyectil de obsidiana y varios artefactos líticos, así como bordes de ollas sin cuello, y otros fragmentos con decoración incisa y en relieve de pasta anaranjada y engobe rojo atribuidos al período Formativo.

\section{Toctococha B (T4)}

Agrupación aldeana, ubicada en el lado norte del riachuelo frente a Toctococha A. Se caracteriza por presentar siete recintos circulares de 2.50 a $3 \mathrm{~m}$ de diámetro, distribuidas junto a nueve recintos de $16 \mathrm{~m}$ de diámetro, todo asociado a un corralón de planta semicircular con dos pequeños recintos circulares donde debió instalarse la persona encargada de cuidar a los camélidos. Entre el material diagnóstico asociado a la superficie existen bordes y asas de ollas y cantaros, apéndice con incisión sin iconografía, puntas de proyectil, raspadores, lascas y láminas, hechas de basalto, riolita, cuarzo, andesita, etc.

\section{Toctococha C (T5)}

Agrupación aldeana, localizada al norte de Toctococha A y al Oeste de Toctococha B, distante a $50 \mathrm{~m}$ del borde de la laguna, las estructuras se extienden hacia las faldas de los cerros contiguos. Se trata del asentamiento aldeano principal, con mayor cantidad de recintos circulares, rectangulares, semicirculares, patios y corralones asociados, pero con escasa presencia de fragmentos de cerámica y artefactos líticos entre puntas de proyectil, núcleos, cantos rodados, fragmentos de azadas hechas de andesita y basalto. En la ladera del cerro existen varios abrigos rocosos, algunas con manchas de hollín y estructuras funerarias, otros abrigos presentan ofrendas tradicionales o pagapus, dejadas para los Apus y la Qochamama vinculados con el cuidado de los animales y la actividad agrícola. 


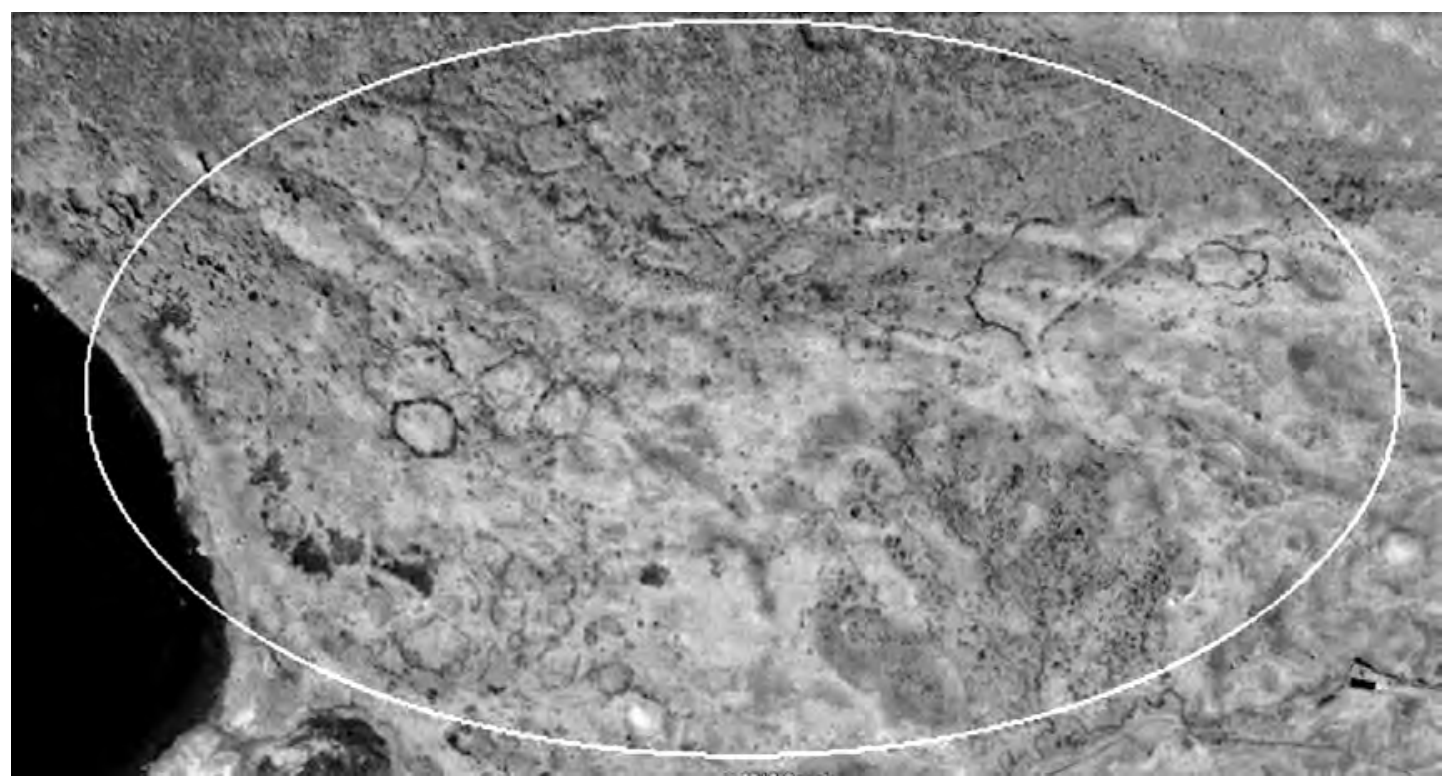

Ubicación de los asentamientos T4 y T5, en foto satelital

\section{Uscococha A (T6)}

Abrigo ubicado en el lado noroeste de la laguna de Uscococha de origen glaciar, a $4000 \mathrm{msnm}$, el abrigo es profundo tiene cerca de $30 \mathrm{~m}$ de largo por $8 \mathrm{~m}$ promedio de ancho y $6 \mathrm{~m}$ de alto, en el techo existe cuatro áreas de hollín, indicadores de la presencia fogones de los antiguos habitantes. En el interior próximo a la entrada se observa restos disturbados de tres estructuras funerarias hechas de piedra y barro, semejantes a los registrados en los asentamientos de Aweloyuq y Ñaupallacta en la parte baja cerca de Tambo. En la superficie logramos encontrar dos fragmentos de cerámica de dos vasijas Wari de estilo Chakipampa; uno es parte del rostro humano de engobe rojo indio, conservándose la nariz en alto relieve con incisiones en las fosas nasales, además de ello posee boca y el ojo izquierdo, con punto negro como pupila y párpados de color negro intenso, el otro fragmento tiene engobe rojo sobre el que aparece figuras geométricas de color negro y crema. En el exterior del abrigo hay plantas silvestres de papa denominadas "pajarupa runtun" por los pobladores del lugar. Los análisis biológicos demuestran que este tubérculo es de una especie primitiva y sumamente tóxico.

\section{Uscomachay A (T7)}

Cueva ubicada al suroeste de Uscococha A, presenta de tres accesos, uno orientado en la parte sur, de forma aparentemente triangular de $2 \mathrm{~m}$ de ancho por $3 \mathrm{~m}$ de alto, a medida que se va accediendo la cueva se hace más ancha, la parte media de la cueva obtiene la forma de una falsa bóveda; un segundo es por el lado norte, con caída que llega hasta el borde de la laguna; y el tercer acceso es por el lado oeste, donde forma otra cueva como parte de la gigantesca roca, este forma una cueva de 1 a 2 $\mathrm{m}$ de alto, $15 \mathrm{~m}$ de ancho por $30 \mathrm{~m}$ de largo, orientado de este a oeste. En esta cueva encontramos un artefacto de forma irregular de $12 \mathrm{~cm}$ de largo por $4 \mathrm{~cm}$, de andesita (instrumento agrícola), también un borde erosionado de cántaro. Techo con manchas de hollín y piso de tierra con claras huellas de actividad doméstica. 


\section{Uscococha B (T8)}

Abrigo localizado al sur de Uscococha A, en el lado suroeste de la laguna a donde da la boca, mide $17 \mathrm{~m}$ de largo, $3 \mathrm{~m}$ de ancho por $3 \mathrm{~m}$ de alto, piso de tierra no alterado, En el lado más alto presenta huellas de hollín en las paredes. En la parte alta exterior al abrigo existe la construcción de una estructura de piedra y barro.

\section{Uscococha C (T 9)}

Abrigo situado al sureste de Uscococha B, formado al pie de un peñasco, mide $18 \mathrm{~m}$ de lago por $6 \mathrm{~m}$ de ancho y una altura de $6 \mathrm{~m}$; piso alterado por intervención del hombre actual que la utiliza para guardado de ganado vacuno, contiene fragmentos de cerámica no decorada, en los alrededores hay gran cantidad de piedras con manchas de cobre cuya beta está en la parte alta de la laguna. El abrigo presenta evidencias de hollín y piedras acomodadas como fogones en ambos extremos del abrigo rocoso.

\section{Uscococha D (T 10)}

Abrigo, ubicado en el lado este de la laguna Uscococha, en tres bloques de roca que forman una hornacina natural, como para cobijar a dos personas, piso no disturbado con artefactos y desechos líticos.

\section{Uscucococha (T11)}

Dique de antiguo represamiento de agua en la naciente de la quebrada de Puñosjasa, la estructura aparece acondicionada con bloques de Champas, conserva una extensión de largo de $15 \mathrm{~m}$ aproximados, $60 \mathrm{~cm}$ de ancho y $1 \mathrm{~m}$ de alto asociado a otros muros que al parecer funcionaban como llaves para drenar y controlar el agua, la actual represa muestra evidencias de reutilización por las gentes contemporáneas.

\section{Puñosjasa (T12)}

Aldea ubicada en la margen derecha de la quebrada Puñosjasa, las estructuras son de forma circular y semicircular, dispersas en una extensión que supera los $500 \mathrm{~m}$ de largo por $10 \mathrm{~mm}$ de ancho, presentan muros de doble hilada asociados excepto los corralones que son de una sola hilada. Existen estructuras rectangulares de pastores actuales. La superficie del lugar carece de cerámica y artefactos líticos, por la ubicación cerca de la laguna y la quebrada es probable que se trate de una población dedicada a la crianza de camélidos de los inicios del periodo Arcaico.

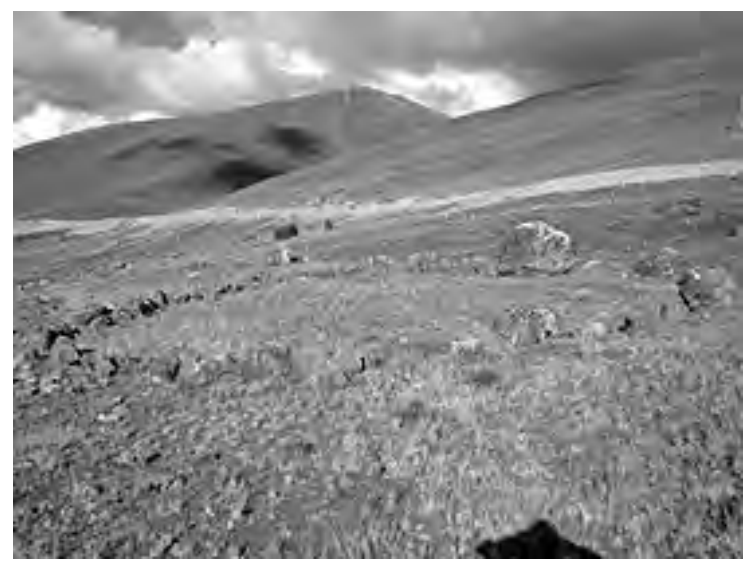

\section{Puñosjasa A (T 13)}

Se encuentra en la margen izquierda de la quebrada de Puñosjasa a $88 \mathrm{~m}$ del riachuelo que llena de vida la vegetación; se trata de una roca de $1.40 \mathrm{~m}$ de ancho por $2.50 \mathrm{~m}$ de alto y $5.70 \mathrm{~m}$ de largo con evidencias de quema (hollín), localizándose 3 tullpas. A $3 \mathrm{~m}$ de distancia hay una caída de detritus (piedras partidas) que son desplazados del cerro Matara.

\section{Puñosqasa B (T14)}

Apacheta situada entre dos quebradas una de ellas es Puñosjasa. Ambas se unen y forman la quebrada Yanamitu; Adyacente a la estructu- 
ra de descanso de carácter ceremonial, existe estructuras aglutinadas de planta circular de diferentes dimensiones, predominando algunas que se encuentran cerca de corralones. Muchas de estas estructuras han sido modificadas por pastores actuales que la utilizan como viviendas para el cuidado de ganado, destaca un amplio espacio abierto que debió ser utilizado como plaza comunal delimitado por un alineamiento de piedras que le otorga una función ceremonial.

\section{Matará (T15)}

Aldea de pastores-agricultores, presenta recintos circulares y semicirculares asociados a corralones, dispersos en la falta sureste del cerro Matara, en la margen izquierda de las quebradas Yanamitu, Ichupata y Pisjohilca, en las cercanías del lugar existe chacras con cultivo de papa nativa, olluco y mashua.

\section{Ñaupallaqta/Millpo (T16)}

Complejo agrícola-habitacional, cortado por la carretera Tambo-San Miguel, las evidencias se observan en ambos lados, pero en el lado sur es el de mayor extensión y monumentalidad, los recintos tienen planta circular, las evidencias llegan hasta el área que ocupa el poblado de Millpo por donde se aprecia el tramo de un camino antiguo en dirección este-oeste junto al cual van los restos de un antiguo canal de agua que viene desde Huanchuy para regar a diferentes chacras o áreas de cultivo en una extensión aproximada de 3 has. En toda la extensión se observa restos de unidades habitacionales circulares y rectangulares, construidas sobre distintos niveles de terrazas algunos recintos llegan hasta $9 \mathrm{~m}$ de diámetro por $1.50 \mathrm{~m}$ de alto. Las terrazas se van ensanchando conforme se accede a los montículos, algunas tienen de 1 a $1.50 \mathrm{~m}$ de alto por 10 a $12 \mathrm{~m}$ en la parte baja y 4 a $6 \mathrm{~m}$ de ancho en la parte alta, se observa cerca de 10 terrazas. La zona está cubierta por plantaciones de eucalipto que impiden apreciar su verdadera extensión, algunas tiene más de $80 \mathrm{~m}$ de largo. Existen algunos recintos circulares de 1.20 por $1.70 \mathrm{~m}$ de diámetro que parecen ser depósitos. En la parte baja al pie de la carretera se observa alineamientos de estructuras planificadas con aparentes callejones y espacios abiertos, con recintos circulares y rectangulares, hacia el lado este donde está el otro montículo existe también restos de plataformas escalonadas que llegan hasta el camino antiguo

Recientes excavación clandestinas han dejado expuesto la planta circular de algunas viviendas de $1.20 \mathrm{~m}$ de alto en el extremo sur. El extremo oeste o Ranraqata, se caracteriza por presentar galerías subterráneas con restos de huesos humanos (fémur, cráneo, peroné y tibia), existe además

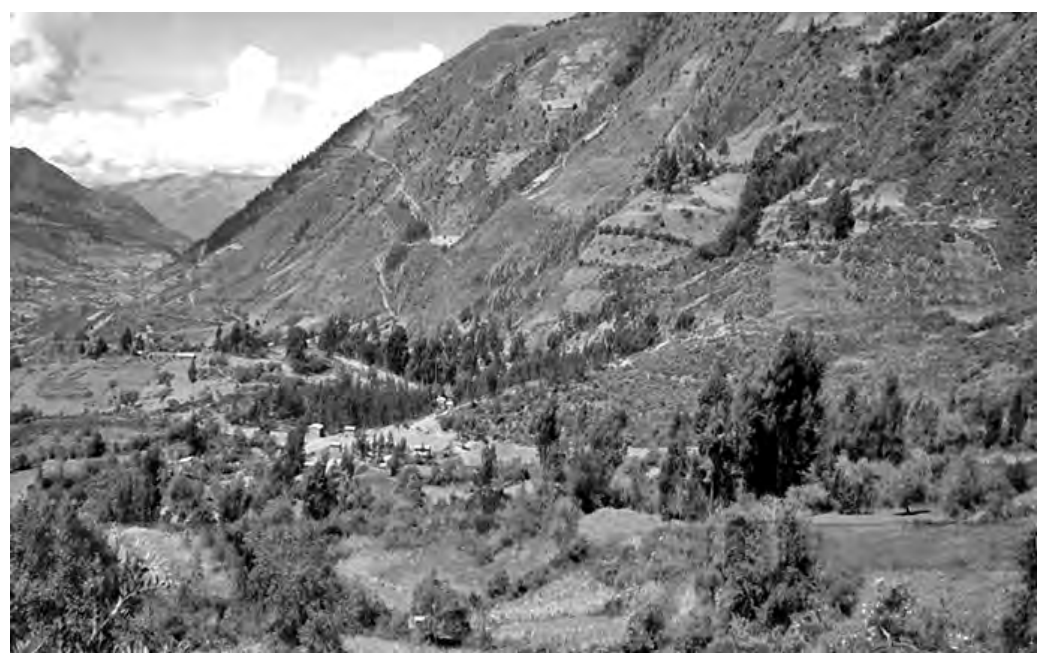
una serie de recintos de carácter habitacional, predominando algunos de planta rectangular. En el extremo opuesto del montículo también hay restos óseos debajo de rocas y piedras grandes al parecer formaron las bases de las chullpas. En la parte media del montículo se observan pozos de cateo clandestino de 1 por $1 \mathrm{~m}$, en el cuál se 

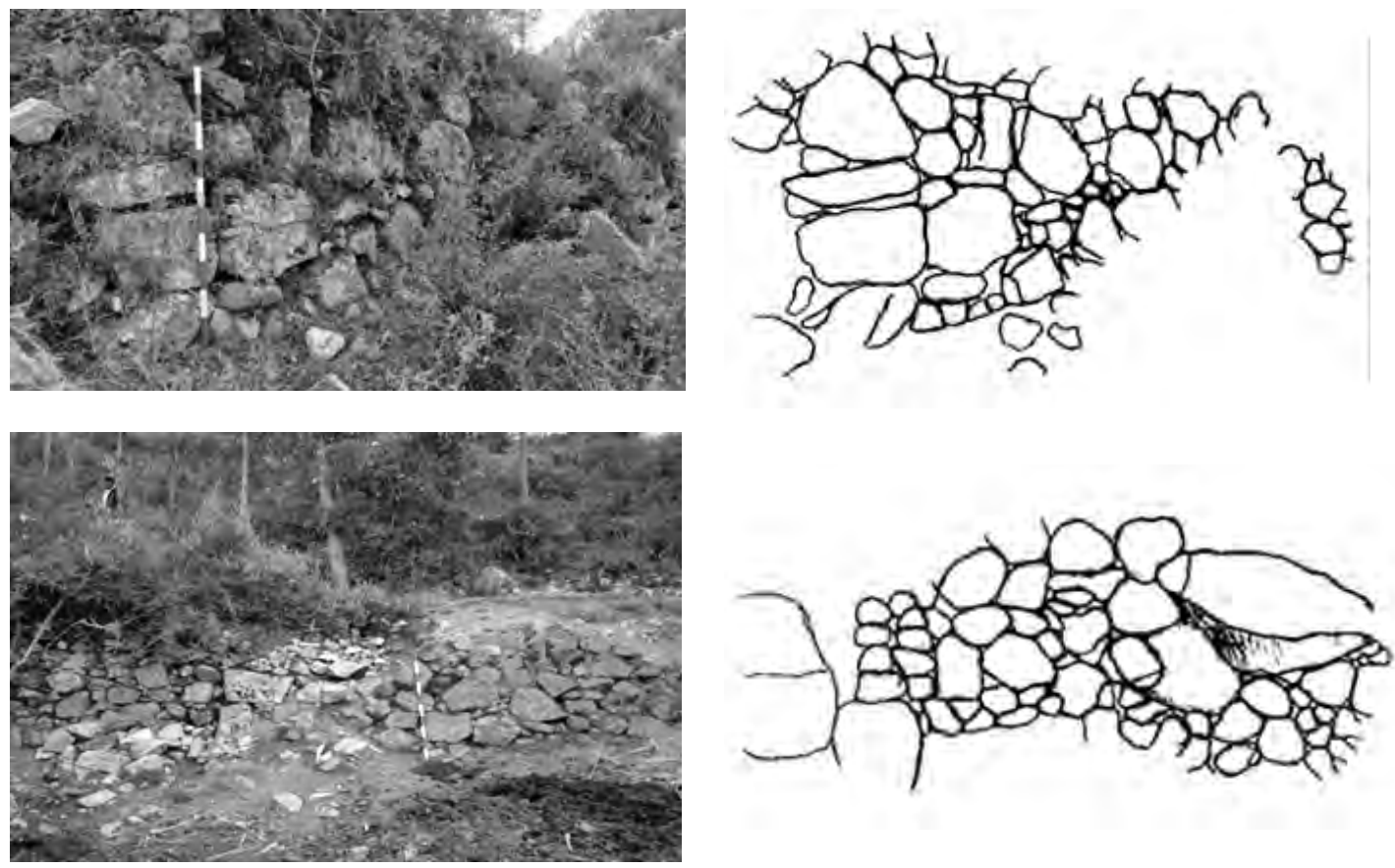

Detalle de uno de las viviendas circulares de Puñaspata (T14)

encuentra abundante material cerámico perteneciente a bordes, cuerpos y bases de vasos, cuencos, y platos; cabe resaltar que se encontró 3 fragmentos con motivos iconográficos de engobe crema con líneas romboidales de color marrón, de filiación cultural Huarpa. También se encontró material lítico como raspadores, pulidores, percutores, hechos de andesita y basalto. Ñaupallaqta ha sido registrado por Hernán Carrillo (1969, 1976 y 1984); Mario Benavides (1976) bajo la sigla de "Ed 1", y sectorizado por Adán Castilla (2001) La parte seccionada pertenece a la familia Medina Pérez y Rivera de León

\section{Marquinayuq (T17)}

Cámaras funerarias, construidas en las peñas del lado noroeste del cerro Huanchuy, lado que corresponde a Mollepucro, (lado oeste de Ñaupallaqta), ocupan el espacio de un abrigo rocoso de $9 \mathrm{~m}$ de largo por $4 \mathrm{~m}$ de alto; en el resaltan las construcciones de 3 cámaras, de las cuales 2 (lado este y oeste) que se encuentran profanados, solo se conservan los muros laterales que conservan $80 \mathrm{~cm}$ de alto, mientras que la cámara central conserva casi la integridad de la forma, presenta la parte frontal del techo y lados laterales de los vanos de acceso, el espesor de los muros es de $20 \mathrm{~cm}$, por $1.35 \mathrm{a} 1.40 \mathrm{~m}$ de alto, están hechas con piedra canteada y mortero de barro, con las caras lisas al interior; a diferencia de las cámaras laterales, está cubierta con argamasa de barro fino de color blanco en la parte inferior.

En Mollepucro existen otras cámaras una de ellas está a $50 \mathrm{~m}$ al oeste y mide 1.80 de alto, con paredes hechas de una sola hilada. El tiempo y la densa vegetación espinosa impidieron registrar otras cámaras que los campesinos de la zona conocen. Este sistema de enterramiento guarda relación con el poblado de Ñaupallacta y las tres cámaras indicadas en líneas anteriores deben responder a un patrón de enterramiento para la élite gobernante. 
a)

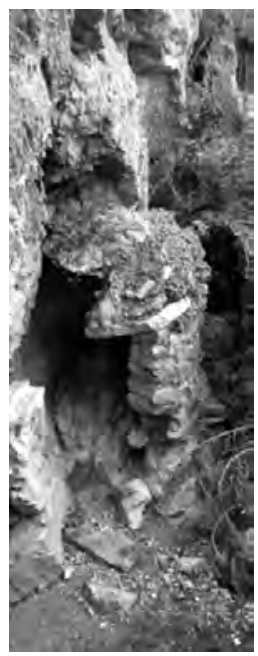

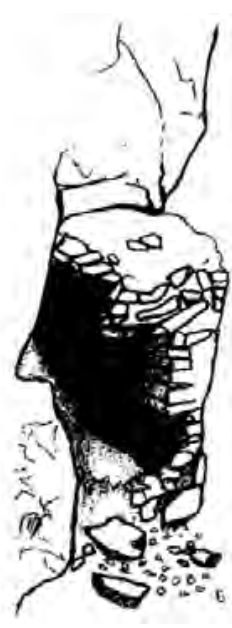

b)

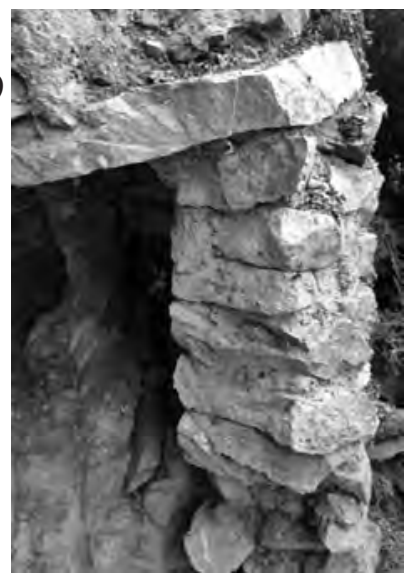

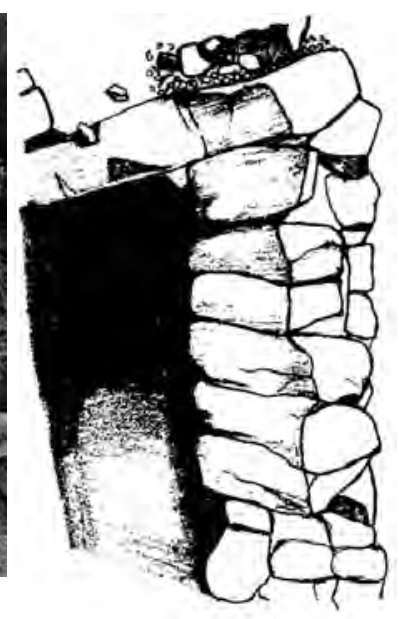

Sitio arqueológico de Marquinayuq o T17,Nótese la forma y el sistema constructivo de las cámaras.

\section{Quintu Urqu Pampa (T 18)}

Estructuras de habitaciones, localizadas a un km al noreste de Ñaupallacta, en la margen derecha, cerca del cauce longitudinal del río Torobamba. Las estructuras son de forma circular y rectangular separadas unas de otras alrededor de una circular mayor de $20 \mathrm{~m}$ de diámetro. Uno de los recintos circulares mide $3 \mathrm{~m}$ de diámetro por $60 \mathrm{~cm}$ de alto, encierra a una estructura subterránea que parece ser una galería funeraria. Las estructuras están asociadas a los restos de un camino antiguo usado por los pobladores del lugar, pozo u ojo de agua y a una piedra ceremonial delimitada por una estructura circular de $20 \mathrm{~m}$ de diámetro con acceso orientado hacia el oeste, en la loma de propiedad del Sr. Luis Quispe, donde a la vez existe una piedra tallada que representa la forma del cerro que se encuentra en el lado este, la piedra mide $2 \mathrm{~m}$ de largo por $1 \mathrm{~m}$ de alto, es considerado como la imagen del apu "Quintu Urqu" de donde proviene la denominación del lugar.

\section{Ccochqa (T19)}

Estructuras chullparías con restos óseos en la parte alta del lado sur occidental del cerro Quinta, al sur oeste de Tambo, se accede por el camino de herradura que va hacia la comunidad de Ccochqa. Consiste en diferentes muros de contención, cabeceras de recintos de planta circular, y murallas que rodean al cerro cuya cima está a $3660 \mathrm{msnm}$.

\section{Quintu Urqu (T20)}

Estructuras habitacionales dispersas en la parte superior del cerro Quintu (3660msnm), parte baja de Tambo, se observa muros de contención ligeramente inclinados, asociados a restos de un camino prehispánico que viene de Chuqitaqi y se proyecta hacia el sur. En la misma cresta de la colina existen varios recintos circulares habitacionales, unos determinados a nivel de cabecera y otros presentan muros de 40 a $60 \mathrm{~cm}$ de alto de doble hilada con mortero de barro, dispuestos alrededor de pequeños patios. La sección central de la cima parece haber sido el núcleo de la población no menor de 2000 habitantes por el mayor número de recintos de planta circular y rectangular acondicionados al afloramiento rocoso del cerro, utilizado en partes como áreas de entierro, por la presencia de huesos humanos disturbados de contextos funerarios, y diferentes niveles de terrazas que se proyectan por 
toda la ladera oriental y el lado sur, siguen los pequeños espacios rodeados de muros, destacando la presencia de por lo menos 4 chullpas y algunos recintos circulares dispuestos a manera de torreones desde donde se domina el panorama del valle. En la superficie existe abundante fragmentos de cerámica de uso doméstico, de esta zona proceden diversos objetos entre vasos, cucharones, piruros, platos, figurinas, ollitas, etc.; que algunos pobladores de Tambo conservan como reliquias. El lado occidental del cerro tiene pendiente accidentada con algunos muros de contención, mientras que en el lado suroeste, existen restos de dos Cochas o fuentes de agua que justifican la ocupación del antiguo poblador. Para visitar las ruinas se accede por el lado norte desde la comunidad de Wayao, o bien por el lado oeste, siguiendo el camino de herradura desde la comunidad de Paqcha. Quintu Urqo aparece registrado por Hernán Carrillo (1969, 1976 y 1984) y Mario Benavides (1976)


Cerámica Chanka, colección familia Pérez, procede del sitio Quintu Urqu (T20)
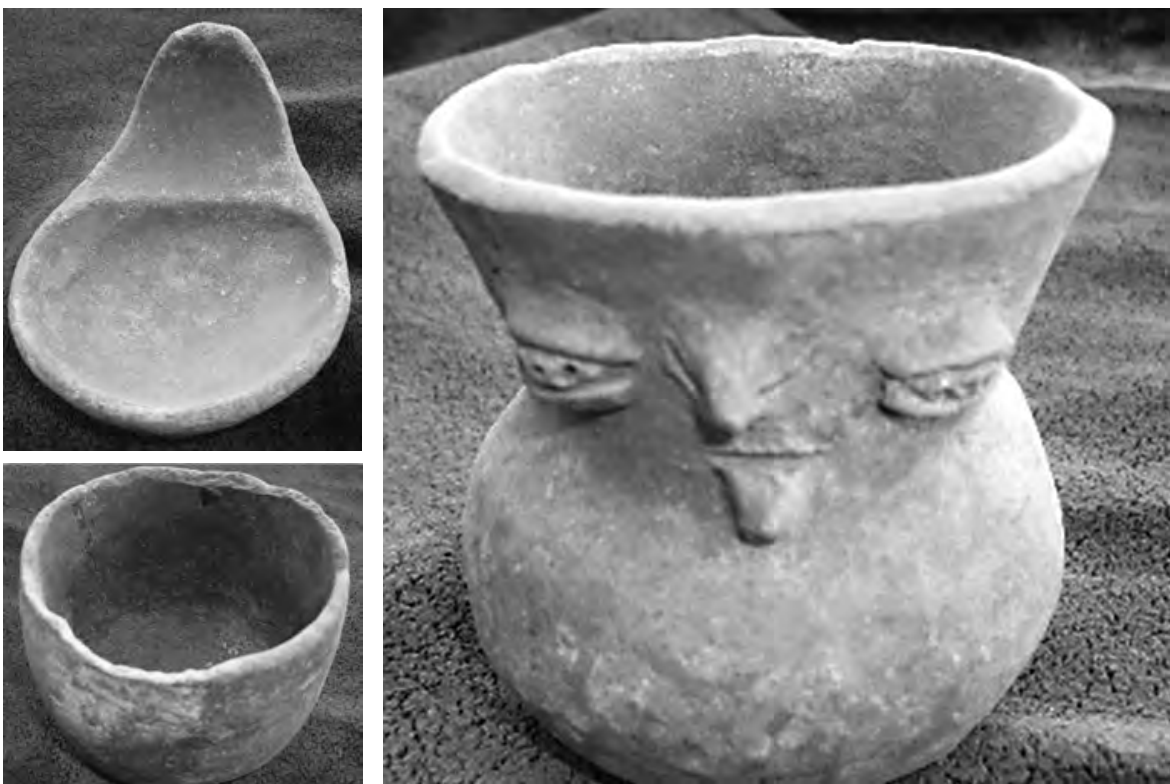

Cerámica Chanka, procedente del sitio Quintu Urqu (T20), colección familia Pérez 


\section{Ccochas (T21)}

Estructura habitacional de planta rectangular, conserva una hornacina cuadrangular de $1 \mathrm{~m}$ de alto por $1 \mathrm{~m}$ de ancho, el muro del recinto mide $2 \mathrm{~m}$. de alto, cubierto por la vegetación espinosa y plantas de eucaliptos que impiden tomar medidas. Adyacente a la estructura indicada existen otros recintos con grandes espacios amurallados de $30 \mathrm{~m}$. de ancho por $50 \mathrm{~m}$ de largo, donde existe piedras apiladas procedentes de las estructuras arqueológicas destruidas por actividades agrícolas. En la superficie del terreno abundan fragmentos de cerámica de estilos Huarpa, Wari y Chanka. Las estructuras ocupan la parte baja del lado este del cerro Quintu Urqu, a las que se accede por la trocha carrozable Tambo-Ccochas.
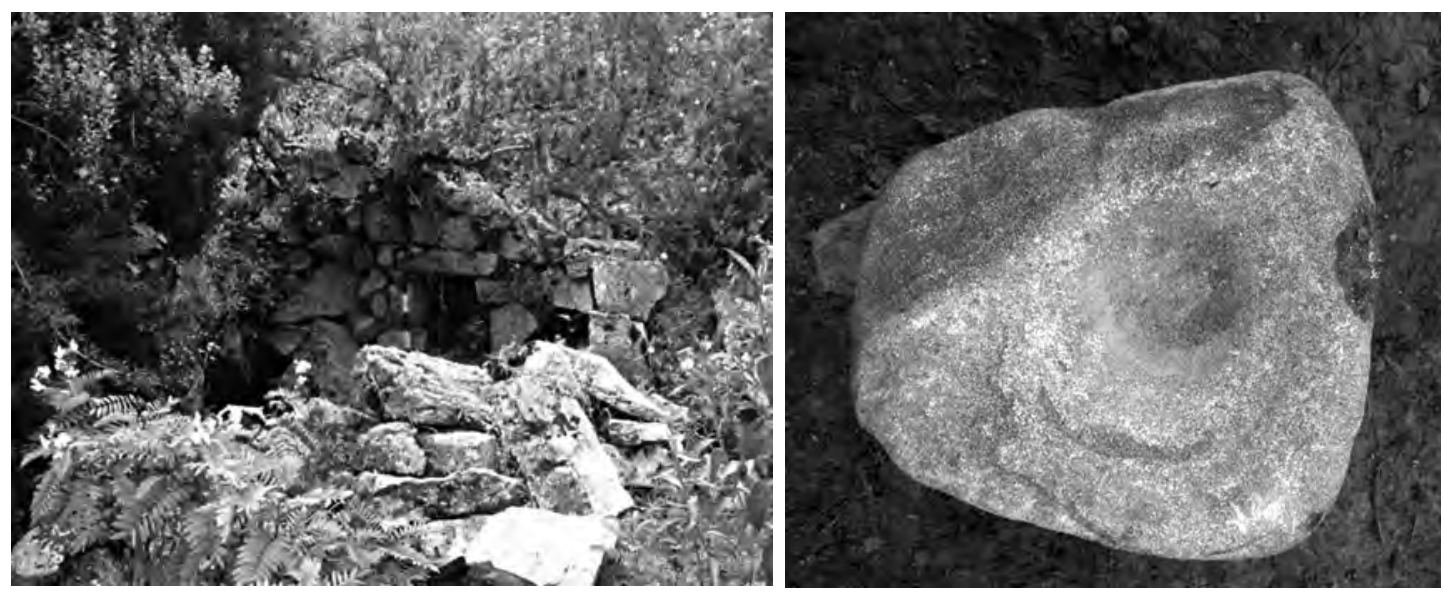

Unidad habitacional de planta rectangular con hornacina

\section{Kurmacu (T22)}

Corralones delimitados por altos muros de piedra procedente de estructuras arqueológicas, las estructuras se ubican en el lado noroeste de la comunidad de Ccochas, por donde pasa el camino principal que se orienta de este a oeste, el cual viene siendo reutilizado, un tramo del camino presenta parapeto en uno de los lados, y en las cercanías existen restos de terrazas y cabeceras de muros.

\section{T 23. Inkaqaqa (T23)}

Estructuras de corralones, muros con nichos y cabeceras recintos, asociados en la superficie del terreno con restos óseos así como bordes, cuerpos, y asas de cerámica de los períodos Huarpa y Wari. Se accede al lugar por la carretera Tambo-Wayao.

\section{Chuqitaqi (T24)}

Cerámica de los periodos Huarpa, Wari y Chanka, óseos y material lítico en cuarzo, en los que destacan lascas, láminas y núcleos, así como cantos rodados con desgate, dispersos en terrenos de cultivo en la parte baja de Chuqitaqi, a $3 \mathrm{~km}$ en línea recta al este de Tambo, siguiendo la carretera que va a Wayao.

\section{Antenachayuq (T25)}

Restos de estructuras habitacionales localizadas al noreste de Tambo, en las faldas sur orientales del cerro Marca, al suroeste de la comunidad de Masinga. Presenta material cultural disperso en medio de chacras que se inician desde la carretera hasta la parte alta donde existe una antena de telefó- 
nica (de donde viene el nombre moderno del sitio), instalada sobre una plataforma con cabeceras de muros, y cerámica de los períodos Formativo, Huarpa y Wari; así como artefactos líticos entre hachas, raspadores, núcleos y raederas en cuarzo, andesita y cantos rodados.

\section{Puka Loma (T26)}

Cerámica Wari de estilos Chakipampa y Huamanga dispersos en la superficie de chacras de cultivo, delimitadas con pircas hechas con piedras procedente de estructuras que debieron existir principalmente en los lados norte y sur del lugar conocido como Puka Loma; Ubicado en terreno arcillosos de coloración rojiza al norte de Masinga.

\section{Loma Aynas (T27)}

Cerámica Wari de estilo Huamanga y de producción local dispersa en la superficie de terreno alterado por labores agrícolas y cortada por la carretera que va de Tambo a Uchuracay, en las inmediaciones del actual centro poblado de Asno.

\section{Jasa Ira Waqta (T28)}

Cerámica y lítico dispersos en la superficie del lado noroeste superior del cerro Marca, al norte de Tambo, cerca de Asno, terreno de propiedad de Sra. Juana Cordero Torre; precisamente en el área donde se han instalado torres de electrificación, con pozos de cateo que demuestran de manera fehaciente el contenido cultural del terreno, incluyendo un corte estratigráfico con restos de una probable unidad habitacional. La cantidad de fragmentos de cerámica indica una densa ocupación doméstica de las épocas Huarpa y Wari. En el material lítico destaca la presencia de lascas de obsidiana, cantos rodados con desgaste en los extremos, asadas y azadones de andesita; estos últimos indicadores de actividades agrícolas y artesanales.

\section{Marca (T 29)}

Estructuras habitacionales dispuestas en el lado occidental y parte superior del cerro del mismo nombre, ubicado a dos $\mathrm{km}$ en línea recta al norte de Tambo. La superficie del terreno contiene abundante material cerámico de los periodos Formativo, Huarpa Huari local tardía; restos de una muralla en el afloramiento rocoso que rodea la cima desde donde se visualiza los valles de Tambo y San Mi-

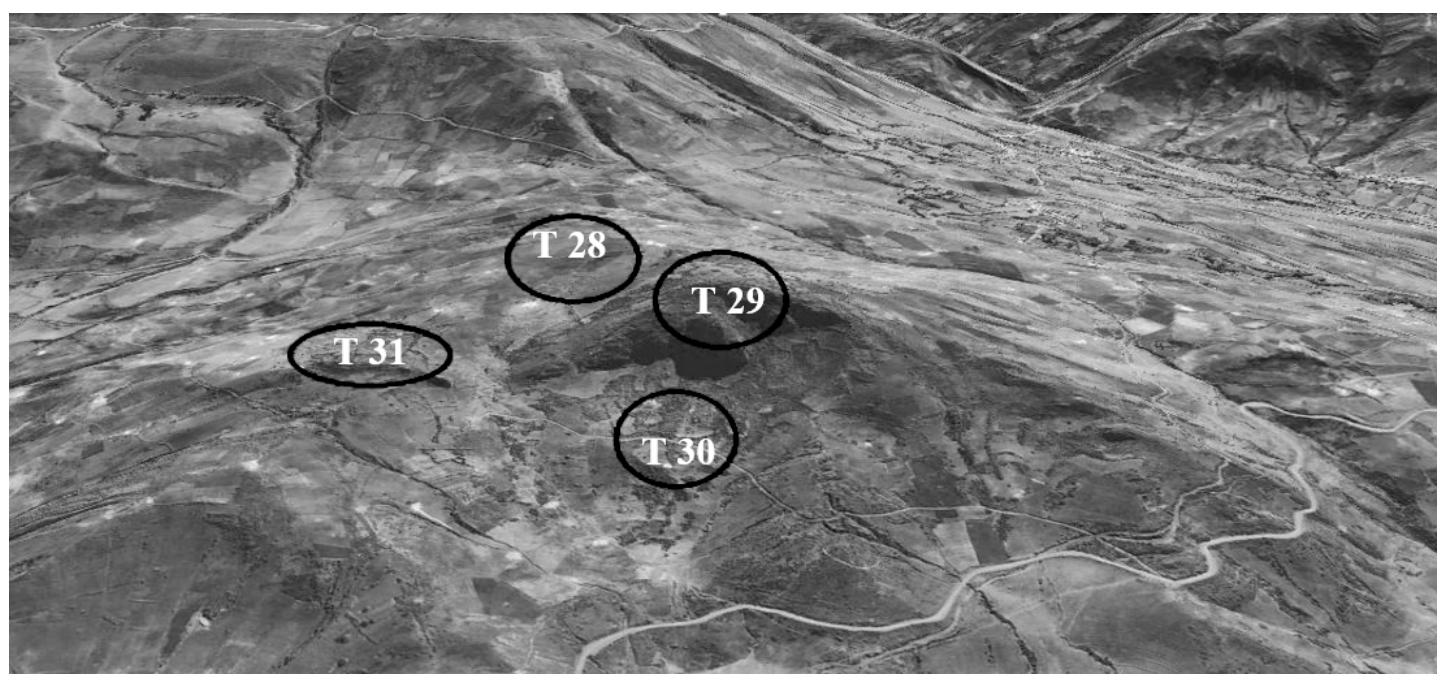

Vista satelital de los sitios arqueológicos de: Jasa Ira Waqta "T 28", Marca "T 29", Marca Waqta "T 30", Cementerio Waqta "T 31" 
guel. Además de las estructuras habitacionales, existe una cavidad rocosa de gran profundidad cuyas paredes y techo presentan huellas de hollín, los campesinos del lugar manifiestan que en la época de violencia, este lugar fue utilizado como "pacas" por miembros de Sendero Luminoso. En este mismo lado existen también estructuras funerarias en nichos y cámaras adosadas a las cavidades de las peñas, así como galerías con huesos humanos, de claro patrón de entierro Wari, cubierto por una densa vegetación que impide conocer la distribución espacial de las evidencias que incluyen los lados sur y norte del cerro Marca, en el lado suroeste sobresale un abrigo con cavidades talladas en la misma roca. De este lugar procede una porra de 6 puntas hecha de andesita.

\section{Marca Waqta (T30)}

Terrazas dispuestas en la margen izquierda de la quebrada Cachupampa y lado oeste del cerro Marca, localizado a menos de $3 \mathrm{~km}$ en línea recta al noroeste de Tambo. Las terrazas se extienden desde la falda hasta la parte alta del cerro, están asociadas a un canal que drena hacia el lado oeste, aparece en partes destruida por el trazo de una trocha. Existe terrazas que conservan entre 70 a 80 $\mathrm{cm}$ de alto, las terrazas del lado noroeste están siendo reutilizadas por los pobladores del lugar, en la superficie hay abundante material cerámico, de los períodos Huarpa y Wari.

\section{Cementerio Waqta (T31)}

Cerámica y material lítico dispersos en el área que ocupa el actual cementerio de Waqta, a lo que se agrega las piedras de las estructuras arqueológicas reutilizadas en la construcción del muro perimétrico y recintos funerarios actuales, el material cerámico es visible en la superficie y morteros de las nuevas construcciones. En base a la cerámica recolectada del lado norte podemos inferir que se trata de un asentamiento de las épocas Huarpa y Wari.

\section{Pampa Hermosa (T32)}

Asentamiento arqueológico de las épocas Huarpa y Wari, sobre el que se asienta la comunidad de Pampa Hermosa, a la que se llega por carretera desde Tambo o bien por Michcapampa pasando por Qarwapampa. Por la extensión comprende los siguientes sectores:

Quchapampa, ocupa el lado sureste, de Pampa Hermosa, se trata del lecho de una antigua laguna en cuyo entorno existen cabeceras de muros de probables andenerías.

Pampa Hermosa, corresponde al área nuclear del actual poblado donde se tiene referencias del hallazgo de vasijas de cerámica y una serie de estructuras entre muros, canales y galerías subterráneas encontradas en el proceso de remoción del terreno para la construcción de las actuales viviendas cuyos cimientos y paredes exponen las piedras de las estructuras arqueológicas destruidas, y una variedad de fragmentos de cerámica Huarpa y Wari que se observa en los morteros de las construcciones de piedra, adobe y tapial. En el mismo poblado, los pobladores señalan que en el jirón 20 de Abril, encontraron bastante cerámica, artefactos de piedra y metal, tal es así que la familia Ramos encuentra de manera circunstancial en el patio de su casa dos vasijas (botellas) de filiación cultural Wari (estilo Chakipampa). En el mismo jirón las familias Oré Huicho, encontraron porras de andesita y basalto, y la familia Yanasupo dan cuenta de un tupu/tipa de bronce, al igual que piruros/ torteros y falsos tornos, hechos de basalto oscuro. En el jirón Barrios Altos, la familia Quispe encontró una flauta hecha de bronce, En este mismo jirón, los Yanasupo encontraron un vaso de cerámica de la época Wari.

Kapillapampa, lado norte del poblado de Pampa Hermosa, expone piedras canteadas y talladas de estructuras arqueológicas destruidas, además de espacios abiertos que deben corresponder a patios de probables unidades habitacionales asociados a caminos antiguos que se proyectan al noroeste y sureste. 
Qatun Pampa, o extremo norte de Pampa Hermosa, consiste en amplio espacio utilizado en la actualidad como área de cultivo, los muros que la delimitan si bien son pircas estas están hechas con piedras de estructuras arqueológicas, por donde pasa un camino prehispánico de $2 \mathrm{~m}$ de ancho, con dirección al noroeste, conservándose $1 \mathrm{~km}$ del camino original, asociado con fragmentos de cerámica Huarpa. En este sector Yuri Solier, poblador del lugar, encontró un recipiente hecho de basalto oscuro y un batan que actualmente lo usa en su vivienda.

Rumi Corral, corresponde al lado noreste de la comunidad por donde pasa el camino principal que va al norte, mide $2 \mathrm{~m}$ de ancho por más de $1 \mathrm{~m}$ de alto, comunica con Tambo, y las comunidades altoandinas de Paria y Balcón. En este sector, existe un ojo de agua de donde nace un canal antiguo que recorre junto al camino, el cual sigue siendo utilizado para el actual regadío.

Qatun Rumipampa, lado oeste del poblado principal, existe presencia de estructuras de plantas circulares y rectangulares conservándose las cabeceras de muros, así como grandes espacios amurallados utilizados como chacras.

\section{Pukakichka (T33)}

Cámaras funerarias dispuestas en la ladera y cumbre del cerro Pukakichka, en el lado este de Pampa Hermosa. Consisten en una variedad de estructuras mortuorias, construidas con piedras canteadas a doble y una hilada, algunas poseen argamasa de barro y otras simplemente acondicionadas a la peña y afloramientos rocosos. Se han registrado tres decenas de cámaras visibles entre malezas y

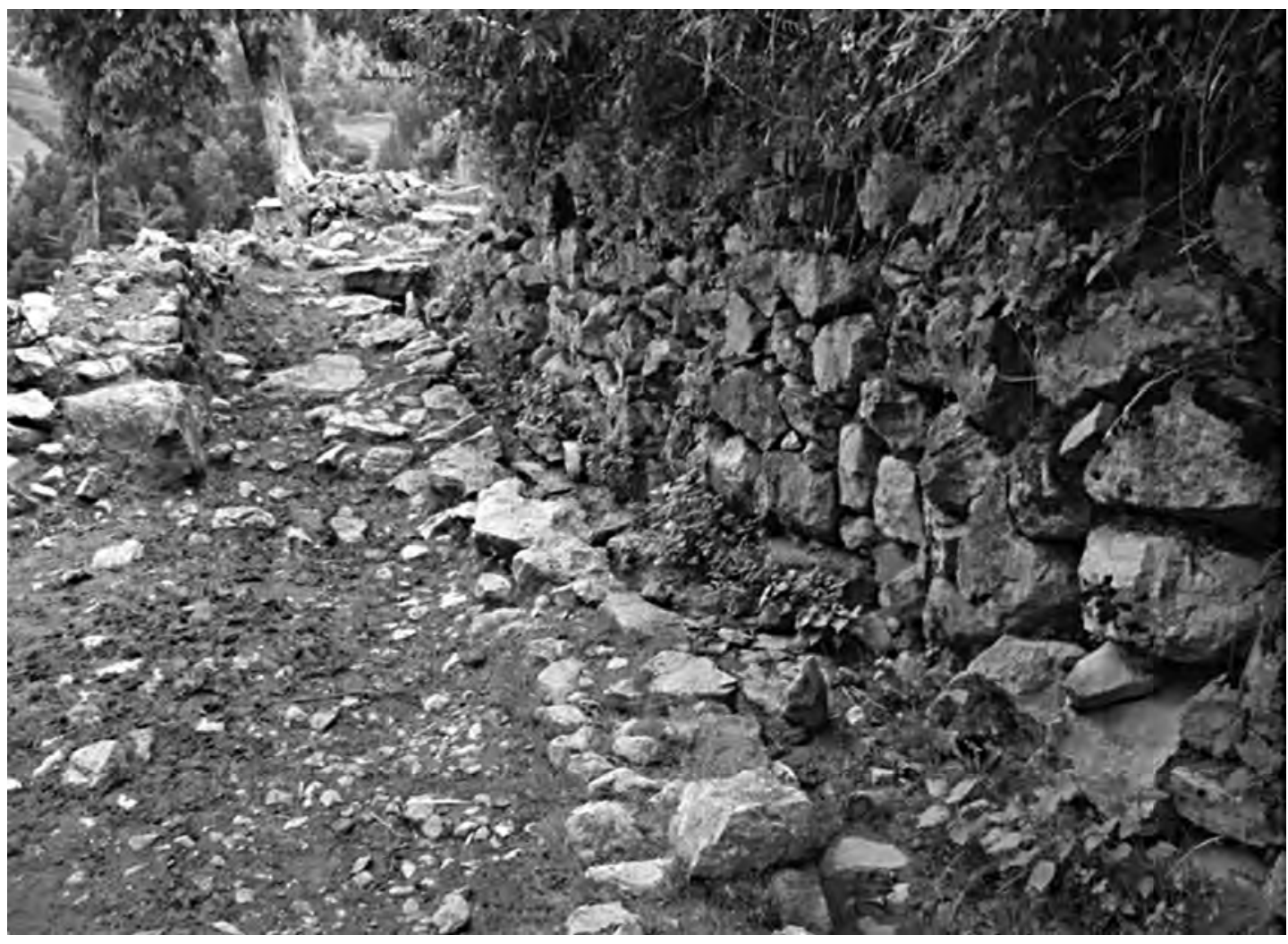

Pampa Hermosa (T 32) Camino y canal en actual uso 


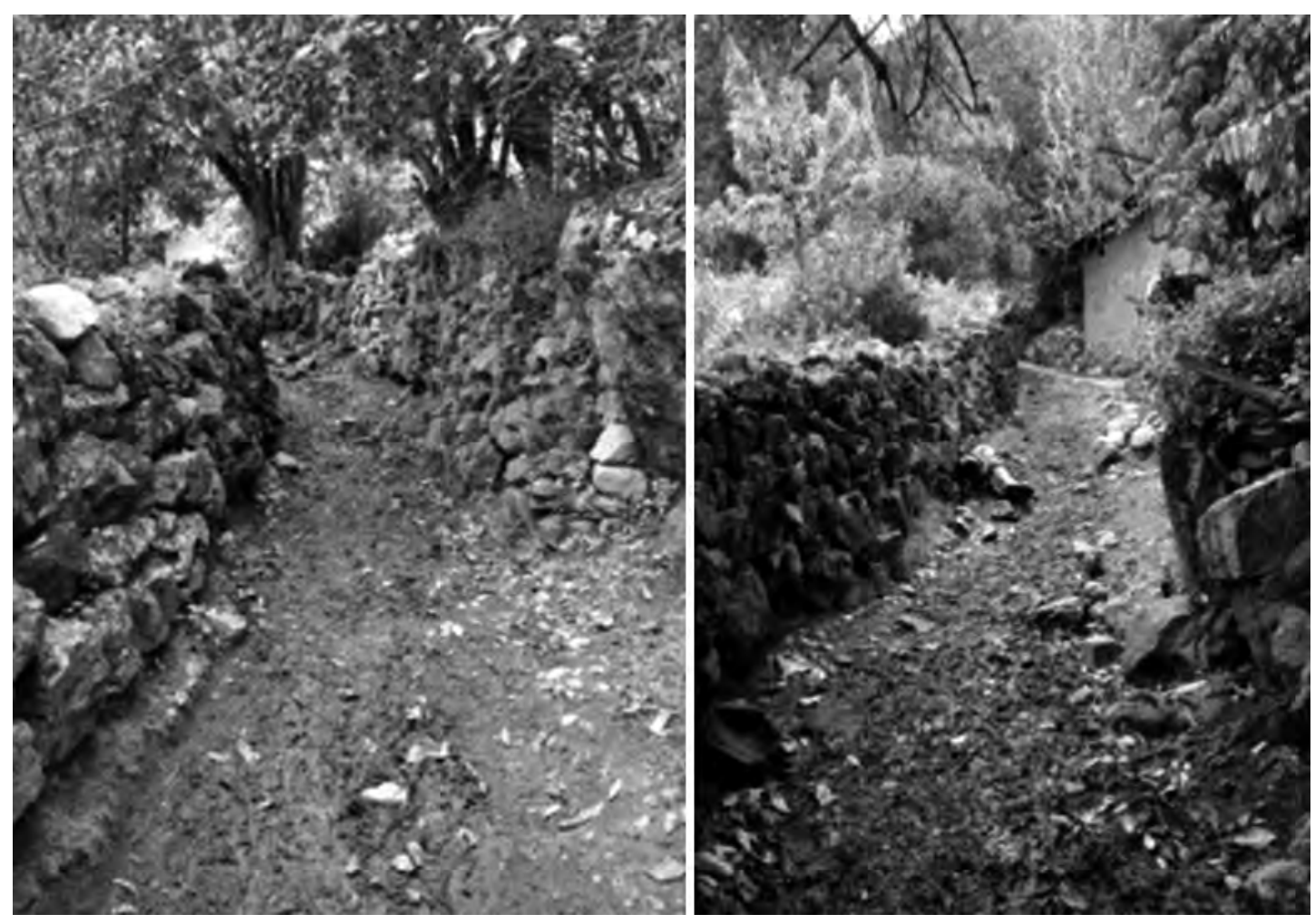

Detalle del camino delmitado con muros de piedra procedente de estructuras arqueológicas
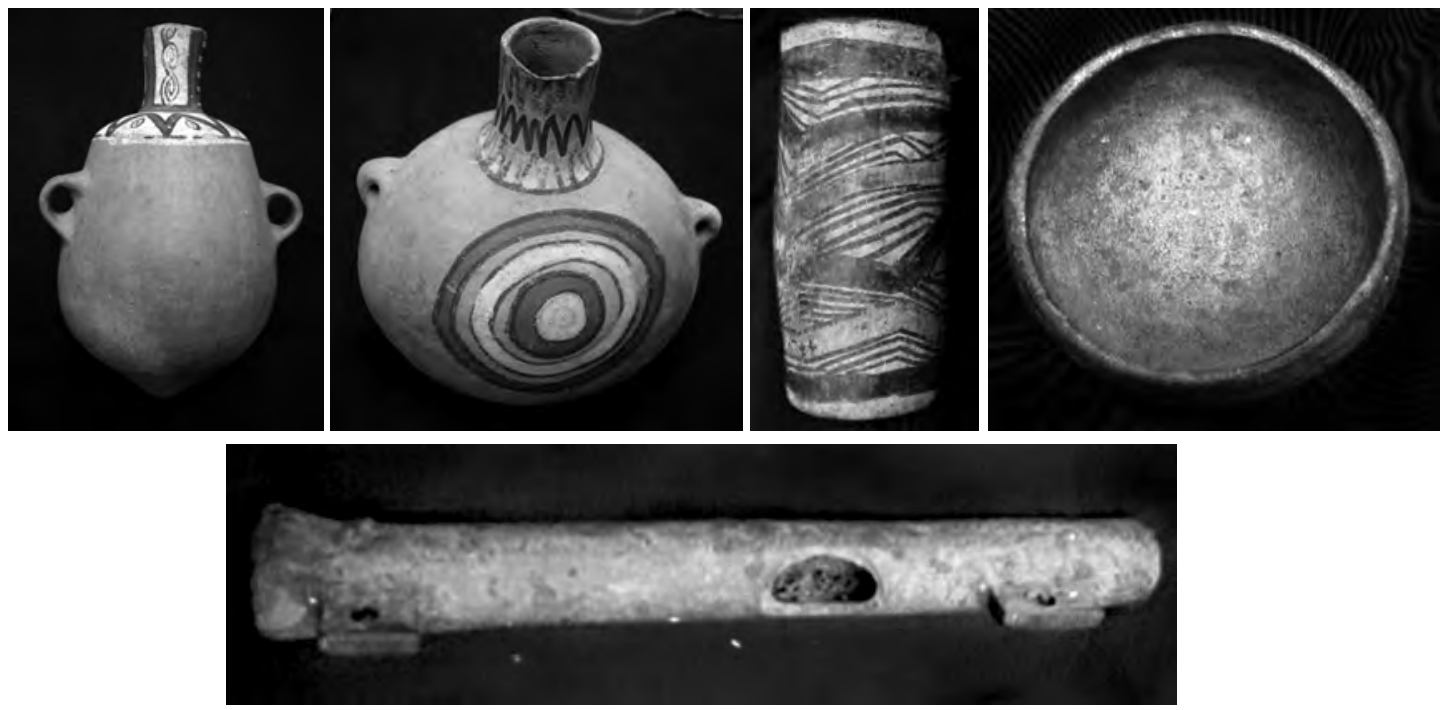

Cerámica Huarpa Tricolor, procedente del sitio Pampa Hermosa (T32), colección Familias Ramos, Quispe y Yanasupo. 


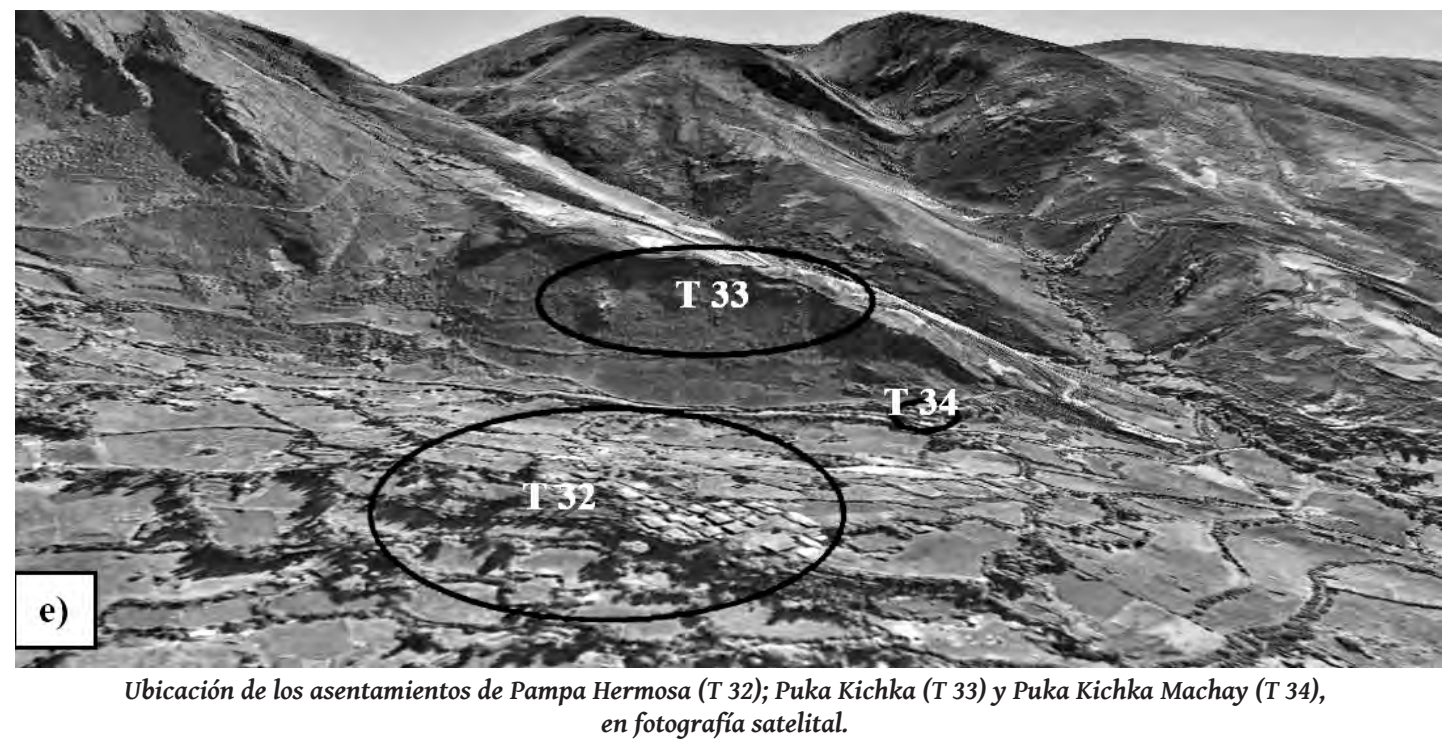

densa vegetación que cubre a otro tanto de cámaras. En la sección media del cerro destaca una cámara intacta con vano orientado en dirección al suroeste y tanto al pie como encima del camino existen otras cámaras, dos estructuras de la parte baja tienen planta circular, acondicionado sobre un abrigo rocoso no muy profundo, con muro de una hilada con argamasa de barro. La parte interna rellenada con piedras pequeñas tipo cascajo. El otro nicho, presenta detalles similares de construcción, pero acondicionada sobre la roca de un abrigo con acceso orientado al oeste. Aproximadamente a $20 \mathrm{~m}$, se encuentra otro abrigo rocoso de mediana profundidad, que contiene una cámara de $1.20 \mathrm{~m}$ de alto por $1.80 \mathrm{~m}$ de ancho, con piso constituido por dos piedras canteadas dispuestas en forma horizontal. El acceso es con dintel de una laja sobre ella se descansa el techo con falsa bóveda, contiene parte del cráneo, fémur entre otros huesos fragmentados de un solo individuo. La pared presenta enlucido de barro impregnado desde la misma roca. A $10 \mathrm{~m}$ aproximados de distancia, siguiendo el camino de herradura, en la parte baja en un acceso accidentado, existe una cámara acondicionada a la peña. La pared presenta parches, indicando haber sido reparada. En el interior se observa fémur, tibia, peroné y otros huesos de un solo individuo. A $50 \mathrm{~m}$ aproximados de distancia, en la parte media del cerro, se encuentra un abrigo rocoso, con una cámara en buen estado de conservación pero saqueada sin restos óseos ni ofrenda alguna.

\section{Puka Kichka Machay (T34)}

Estructuras funerarias en el cerro Pukakichka, se trata de una cueva de $8 \mathrm{~m}$ de profundidad por $1.50 \mathrm{~m}$ de alto, contiene gran cantidad de huesos humanos, dispersas en el interior

\section{Aweloyuq (T35)}

Estructuras funerarias dispuestas en abrigos rocosos y peñas del cerro Aweloyuq, entre la margen derecha de la quebrada Cachupampa e izquierda de la quebrada Yanamito, a tres km aproximadamente al oeste de Tambo. Parte de las estructuras están cerca del camino de herradura que va de Tambo a Huito, algunas estructuras dispuestas a manera de cámaras se encuentran adosadas a las peñas y abrigos, otras construidas a doble hilada sobre el suelo rocoso, pero también existen nichos excavados en la paredes de los abrigos, los dos primeros casos presentan restos de techos con "falsa bóveda". Existen más de un centenar de estructuras funerarias asociadas con huesos humanos disturbados y fragmentos de cerámica de los períodos Huarpa y Wari. 

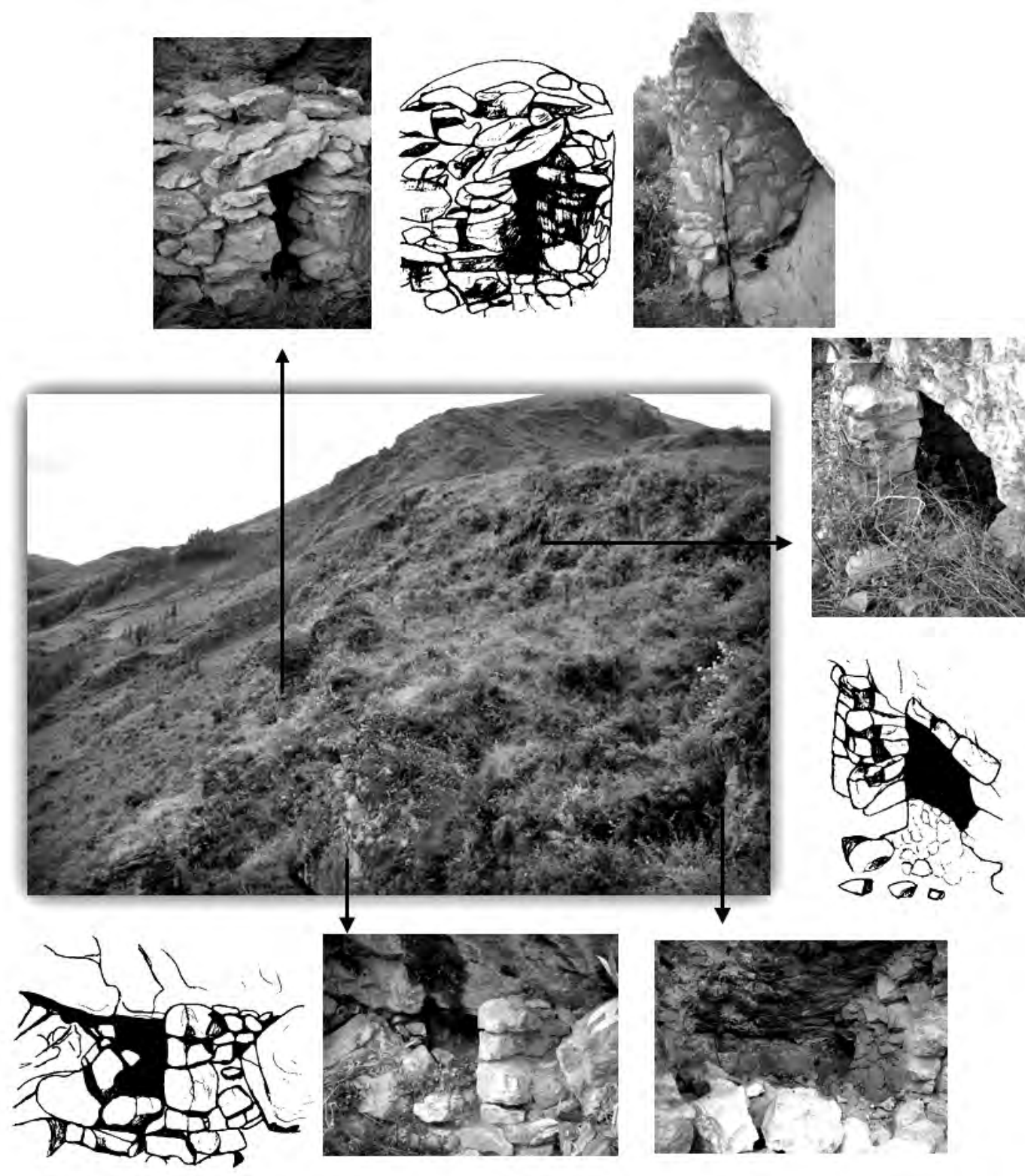

Lado oeste del cerro PukaKichka con entierros tipo cámaras 


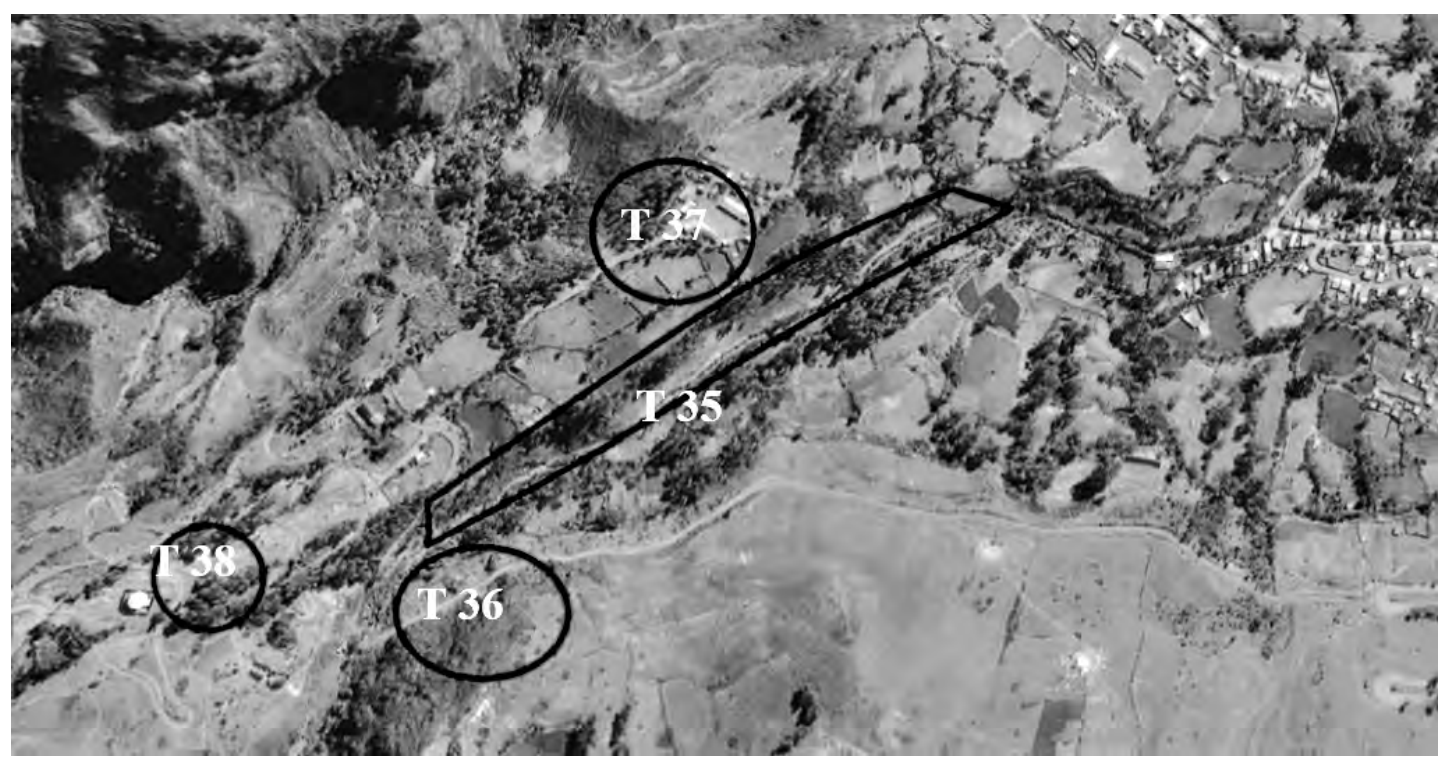

Ubicación de los asentamientos de: Aweloyuq (T 35); carretera Moya-Huito (T36); Chachaspata - la Merced (T 37) y Huito Rumi (T 38) en fotografía satelital.

Carretera Moya-Huito (T36)

Estructuras funerarias dispuestas en las laderas de los cerros Moya-Huito y Aweloyuq a menos de $3 \mathrm{~km}$ al suroeste de Tambo, zona de difícil acceso. De este lugar procede un fragmento de kero de estilo Wari Negro Decorado con decoración incisa que representan la cara del personaje central de la portada del sol o señor de los báculos.

\section{Chachaspata - La Merced (T37)}

Camino prehispánico que viene de Aweloyuq y se proyecta a la cuenca alta de Toctococha; mide $2.20 \mathrm{~m}$ de ancho, en su entorno existe diferentes chacras con restos de estructuras alteradas para
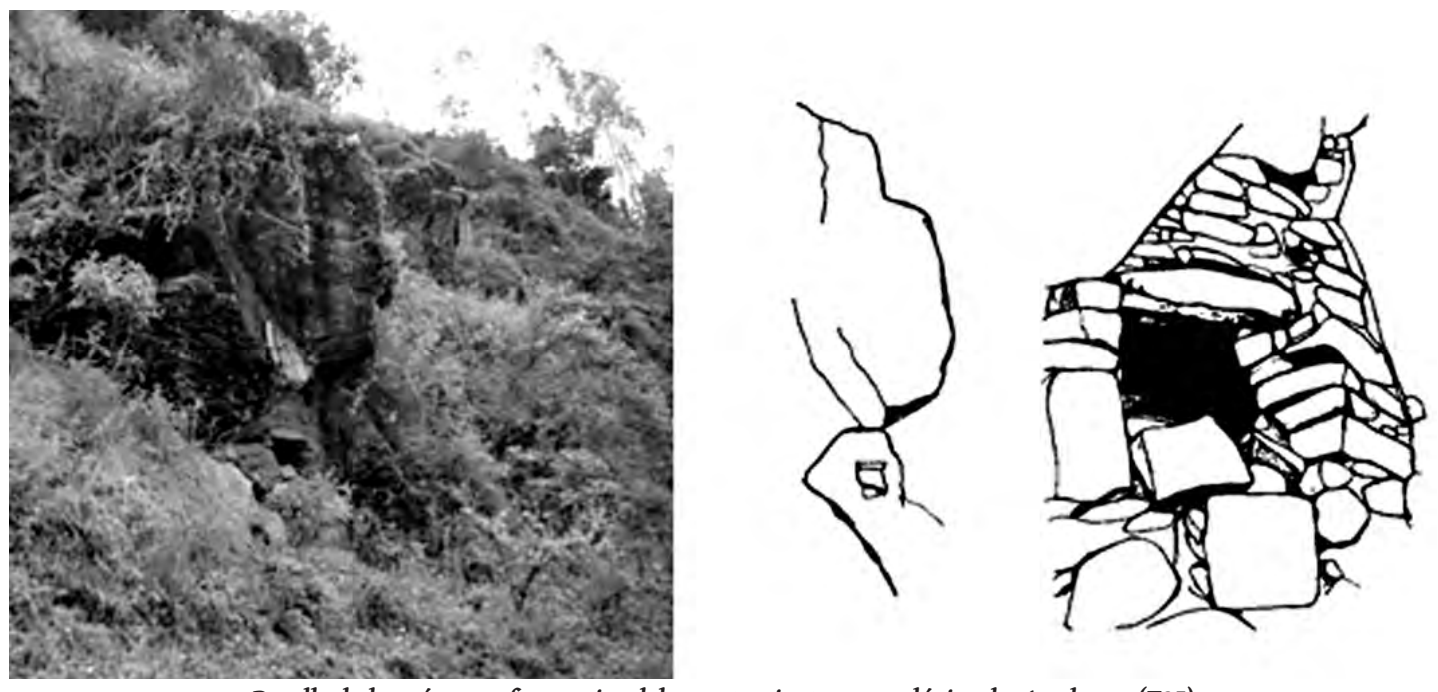

Detalle de las cámaras funerarias del asentamiento arqueológico de Aweloyuq (T35) 


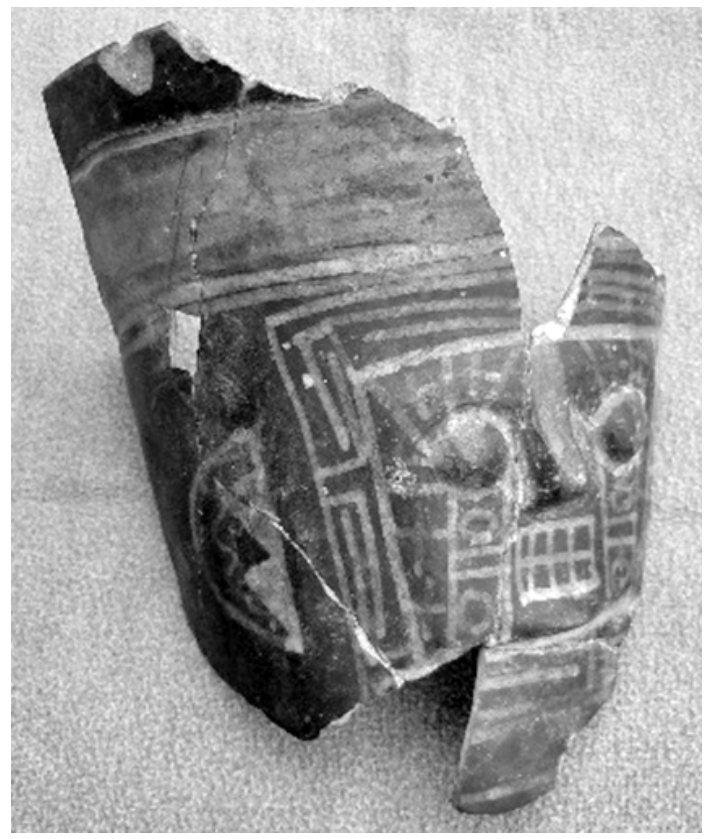

formar pircas y linderos que delimitan terrenos de diferentes propietarios. De esta zona provienen algunos materiales arqueológicos que forman parte de pequeñas colecciones donde existen objetos de metal, cerámica y óseos, destacando una flauta en hueso que conserva Don Augusto Miguel. En otras colecciones existen jarras de engobe negro interno y externo del periodo Wari negro Local, uno de ellos presenta un motivo iconográfico vinculado al culto del agua. Otra jarra, presenta un motivo iconográfico asemejando a un rostro humano, de color blanco sobre negro.

Cerámica Wari Negro influencia Tiahuanco, procedente del sitio Moya-Huito (T36). Obsérvese el rostro de la Portada del Sol.


Cerámica local blanco sobre negro, y artefactos líticos, procedentes de Chachaspata - La Merced (T36) (Colección Augusto Miguel Cardenas) 

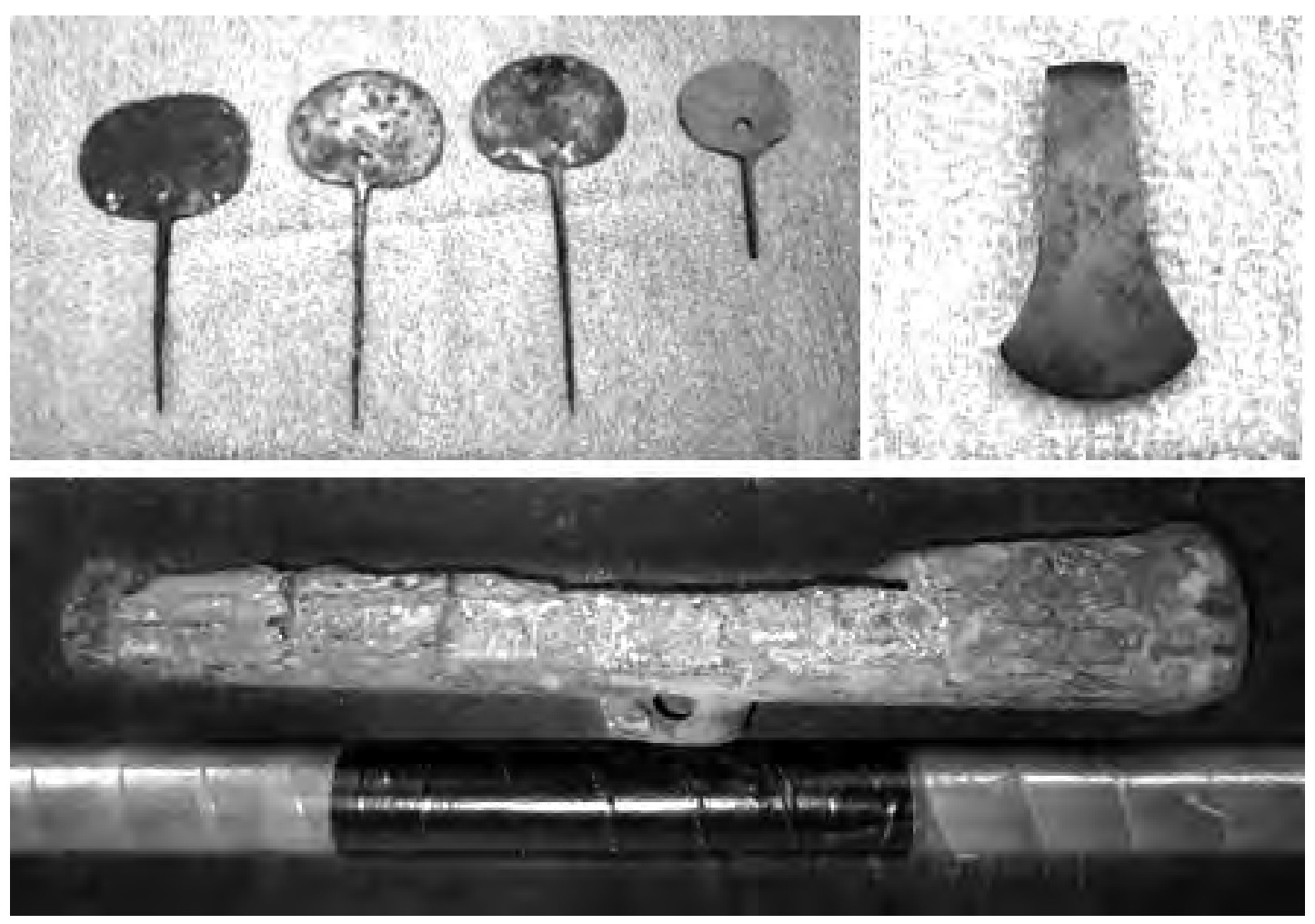

Tupus, Instrumento musical y pinza de metal, procedente de Chachaspata-La Merced (T36), colección Sr. Augusto Miguel Cárdenas.

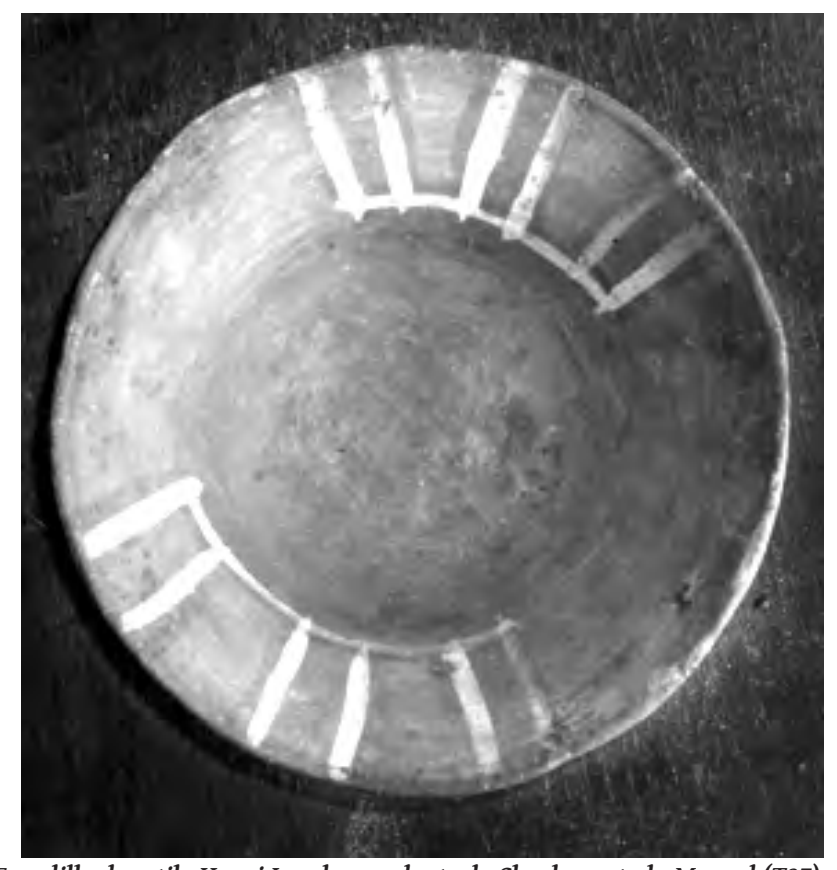

Escudilla de estilo Huari Local procedente de Chachaspata la Merced (T37). 


\section{Huito Rumi (T 38)}

Abrigo y muro prehispánico localizado en el lado oeste de la comunidad de Huito. El abrigo presenta huellas de hollín de distintos fogones, algunos de la época colonial y republicana de viajeros que van a la selva (VRAE), el muro parece corresponder a un recinto o parte de una vivienda.

\section{DisCUSIÓN Y COMENTARIOS FINALES}

Los estudios arqueológicos realizados en el distrito de Tambo y zonas aledañas desde 1969 hasta la actualidad, han permitido documentar la existencia de cerca de medio centenar de asentamientos arqueológicos, ubicados estratégicamente en la cima y laderas de los cerros que integran el sistema orográfico y en las profundidades del valle de Torobamba, afluente principal del río Pampas en la cuenca del río Apurímac, donde la región interandina se une a la ceja de selva formando un territorio especial que facilita entender un claro proceso de culturización sobre el medio geográfico, con patrones de asentamiento determinados a partir del aprovechamiento de los recursos naturales de sierra y ceja de selva andina. En tal sentido, el presente trabajo se alinea en el desarrollo de la arqueología del paisaje buscando añadir y mejorar los primitivos enfoques arqueológicos al estudio de las distribuciones espaciales arqueológicas, a la Ecología de los asentamientos, a los paisajes rituales y a los paisajes étnicos conlleva aspectos importantes de los paisajes. También contribuyen las incursiones útiles e importantes en las dinámicas conductuales de las comunidades del pasado y en sus pautas de cambio (Anschuetz et al. 2001: 182).

Willey (1953), en su estudio sobre patrones de asentamiento en el valle de Virú, costa norte de los Andes centrales registra más de 300 asentamientos que los ubica en diferentes mapas de acuerdo a un orden cronológico basado en el estudio de la cerámica encontrando una secuencia continua pero con mayor ocupación en los periodos que comprende un tiempo aproximado desde los 1800 a.C. a los 1200 d.C, lapso en que se dan los periodos Formativo, Desarrollos Regionales e Imperio Wari por Lumbreras (1969), conocidos también como Cerámico inicial, Horizonte Temprano, Intermedio Temprano y Horizonte Medio por Rowe (1958).

Por su parte, Rouse (1972), sobre el patrón de asentamiento señala que se puede hacer una clasificación siguiendo el grado de nucleación, donde los factores que determinan, en última instancia, si un asentamiento se caracteriza por un patrón disperso, compacto, etc., son los recursos disponibles en la zona, los patrones de subsistencia y la manera concreta en que la sociedad se aprovecha de los recursos, lo que definiríamos como modo de vida. La tipología de los patrones de asentamiento logrados por Irving Rouse, son fundamentales para entender los tipos de asentamientos clasificados de acuerdo a la magnitud, extensión y contenido cultural, sin embargo los grados de nucleación de los sitios arqueológicos en el la sección explorada del valle de Torobamba, conduce a entender en un patrón de asentamiento concentrado en zonas con mayores recursos, dando lugar a la formación de diferentes clases de asentamientos: pequeños, medianos y grandes, lo cual se podrá confirmar cuando se profundicen las investigaciones orientadas a reconstruir el modo de vida de las antiguas ocupaciones y las respectivas áreas de influencia.

De esta manera, planteamos la existencia de 6 núcleos poblacionales: Toctochocha, Naupallaqta, Pampa Hermosa, Cementerio Waqta, Chachaspata - La Merced y Quintu Urqu, de los cuales Ñaupallaqta y Pampa Hermosa, corresponden a centros urbanos que tuvieron un mayor desarrollo en la época Huarpa. Veamos de manera general, las características de los asentamientos identificados y registrados. Trataremos en primer lugar de asentamientos de las lagunas de Toctococha, Uscococha y sus afluentes ubicados sobre 4,233 $\mathrm{msnm}$., donde la presencia de las lagunas, constituye no solo 
un recurso; sino también un lugar de culto, ya que significa laguna madre "mama cocha", donde la tradición cultural de caza y recolección, se mantuvo hasta épocas tardías; coexistiendo las economías sedentarias de agricultores, criadores de animales y pastores relacionados con ritos y ceremonias de culto al agua. De acuerdo a la seriación ceramográfica y las comparaciones tipológicas, pertenecen a las fases media y tardía del periodo Formativo. Estos sitios arqueológicos pertenecen a aldeas y campamentos abiertos; dedicados al pastoreo de camélidos, control del agua (Toctococha y Uscococha) y camélidos para la dieta alimenticia y obtención de lana. Los sitios arqueológicos distribuidos en la cuenca alta de Tocto, presenta estructuras arquitectónicas, construidas con piedras y barro a mampostería ordinaria, de planta circular y semicircular. Además de ello se cuenta con corralones y patios, asociados a unidades habitacionales propio de poblaciones aldeanas. Algo semejante Matos (1971), registra un conjunto de sitios formativos en el valle del Mantaro como parte del "Proyecto Andino de Estudios Arqueológicos", señala que corresponden a pequeñas aldeas, viviendas aisladas y refugios en abrigos rocosos.

En Toccto, la particularidad de las estructuras, es la presencia de dos hileras de piedras paradas como cimentación de una pared constituida por madera, y techo de ichu, amarrados con sogas de fibra vegetal, posiblemente cabuya traída de la parte baja del valle o cascaras de árboles como chachas, qenhua, quinual, etc. Estas formas de muros solo se encuentran en las unidades habitacionales de dimensiones que oscilan los 2.50 a $3 \mathrm{~m}$ de diámetro y obedecen a un patrón arquitectónico de pampas y lagunas alto andinas como las que existen en Pampa Qasa, represa de Toctococha y en las nacientes de las quebradas Puñosjasa y Yanamitu. Algunas poblaciones del periodo Formativo reocupadas durante la época Huarpa, tal como indican las evidencias en los asentamientos de Pampa Hermosa, Acco, Pinchin y Qeqra, cercanos al cauce río Torobamba de donde nacen los canales para irrigar las andenerías en los valles de Tambo donde se encuentran los sitios de Pampa Hermosa, Naupallaqta y Jasa Ira Waqta y otros de menor magnitud como Wayao, Acco, Qeqra, Ccochas, Inkaqaqa, Chuqitaqi; Cementerio Waqta, Marca y Antenachayuq. Lumbreras (1974) manifiesta, que durante la época Huarpa, hubo una considerable población, en la parte baja y alta de la cuenca del río del mismo nombre con sitios ubicados desde los 3,600 hasta los 2,600 msnm. Para Benavides (1971), la distribución de la cerámica Huarpa cubre una gran área que incluye a las actuales provincias de Huanta, Huamanga y La Mar.

De manera particular el asentamiento de Ñaupallacta en Millpo, es un extenso centro urbano con categoría de una posible ciudad, presenta dos montículos asociados a plataformas habitacionales de recintos circulares y rectangulares, conectadas a un camino principal que pasa por el espacio que separa a ambos montículos formando dos sectores, como una suerte de dualidad de Hanan y Hurin. Las evidencias encontradas, llevan a sostener que este asentamiento continuó siendo ocupado como un centro administrativo de gran relevancia durante el período del Imperio Wari u Horizonte Medio, pues la ubicación estratégica en curso superior del río Torobamba; lo convierte en lugar de conexión de acceso al valle de San Miguel donde está el sitio de Qarqampata estudiado por Isbell (1970), y a la selva (VRAE). El otro extremo del camino se proyecta a las alturas de Tocto en dirección a la ciudad de Wari. Por otro lado la presencia de cerámica tardía y de producción local encontrada, en las partes altas de Ñaupallaqta, señala que dicho asentamiento siguió ocupado durante los Estados Regionales, por grupos locales anexados a la confederación Chanka, que se extendió hasta Caballuyoq en la ceja de selva, sitio registrado por Bonavia (1964) y mencionado por Purizaga (1972), en su interesante ensayo sobre el Estado Regional en Ayacucho (periodo Intermedio tardío 1200-1470). Algunos de los entierros en abrigos rocosos con presencia de "nichos", dispuestos en las laderas del cerro de Mollepucro podrían pertenecer a esta época. 
Otro de los centros urbanos Huarpa con características de ciudad es Pampa Hermosa, cerca de otros sitios menores como: Quishuarpata, Mitipampa, Balcón, Paria y Michkapampa. El asentamiento presenta amplios espacios abiertos rodeados de campos de cultivo, que incluye andenerías que cubren las laderas y faldas de los cerros Cebollayuq. Al igual que Ñaupallaqta cuenta con una red de caminos, hacia el norte se conecta con Paria, Polanco y las alturas de Huanta, y por el sur con los valles de Acco que llega hasta Torobamba y Naupallaqta, el camino se extiende a lo largo del valle de Challyamayu, también aparece reocupado durante el período Wari, con presencia de cerámica de estilo Huamanga. Los caminos se hallan asociados a una red de canales, que dominaban admirablemente la parte alta y baja del valle de Tambo.

Cementerio Waqta, es un asentamiento de menor magnitud que Pampa Hermosa, pero con cerámica que indica una larga ocupación desde el periodo Formativo hasta Wari, al ser alterado como uso de cementerio actual los muros de las estructuras arquitectónicas han sido destruidos y ahora forman parte de la construcción del "cementerio de Acco" y linderos de chacras de cultivo, quedando en el lado oeste, un montículo en cuya cima de aspecto circular hay un afloramiento rocoso, fortificado con piedras canteadas. Pensamos que en el periodo Huarpa, fue un importante centro ceremonial. Al lado suroeste se encuentra el sitio de Jasa Ira Waqta, en el cual se encuentra abundante material cerámico del periodo Huarpa, se trata de un recinto circular de probable función funeraria. Al sur se encuentra el sitio de Marca, el cual tiene indicios de haber sido reocupado hasta el periodo de los Estados Regionales, presenta chullpas y cámaras funerarias en abrigos rocosos.

El quinto asentamiento urbano Huarpa ocupa el subsuelo actual poblado de Huito, rodeado de chacras de cultivo, al norte de Tambo. Si bien solo se observan cabeceras de muros, en el lado oeste de Huito queda parte de lo que podría haber sido el núcleo de la zona urbana a la que se atribuye entierros en cámaras dispersas en las laderas del cerro Qaruapampa, donde destaca la zona conocida como Aweloyuq. Chachaspata La Merced, fue el núcleo del centro urbano durante el periodo Wari, presenta cerámica Wari Negro y Huamanga y restos de caminos que conducen a las partes altas y bajas de la cuenca del Torobamba. Probablemente se trate de un centro administrativo Wari, para el control económico de las etnias locales, dispersas a lo largo y ancho del valle de Tambo. Por ahora resulta difícil plantear si fue Ñaupallaqta o Chachaspata - La Merced, el centro administrativo principal del periodo Wari en Tambo.

Finalmente el sexto asentamiento nuclear, es Quintu Urqu, en la margen izquierda del río Torobamba, corresponde al periodo de los Estados Regionales o época Chanka, cuyo patrón de asentamiento, según Lumbreras (1959), es de dos tipos: Collca y Chullpa. Los primeros son agrupación desordenada de construcciones circulares de 3 a $8 \mathrm{~m}$ de diámetro que ocupan las cumbres de los cerros siendo las alturas máxima de sus paredes de 1 a $1.2 \mathrm{~m}$; el segundo tipo sugiere ser funerarias por contener cantidad de huesos disturbados, tienen también planta circular, paredes altas con falsa bóveda y techo de lajas. Lavallee (1983), sostiene que se trata de pueblos que debieron fundarse durante el periodo Wari, a causa de una expansión demográfica, o que una inseguridad creciente, los incitará a buscar sitios protegidos para edificar nuevos poblados. Sin embargo González (1979:71), sostiene que la mayoría de los yacimientos vienen a ser poblados dispersos ubicados en las alturas de los cerros en lugares de difícil acceso, donde los pobladores han aprovechado los accidentes topográficos para construir habitaciones. Para Valdez, Vivanco y Chávez (1990:20), afirman que como negación a los espacios ocupados por los Wari, los distintos asentamientos Chanka de la cuenca Pampas-Qaracha, están por encima de los 3,500 msnm, llegando incluso a los 4,050 msnm., en lugares de difícil acceso y en donde cada asentamiento permite visualizar al resto de los sitios, y gran parte del área circundante. De acuerdo con las propuestas de los citados investigadores Quintu Urqu, es un poblado Chanka, y 
por la concentración de estructuras, aparentemente ordenadas planteamos que el lugar tiene ocupaciones previas, pero que en el periodo de los Estados Regionales fue el pueblo principal o quizá capital de un desarrollo local tardío que surgió con el ocaso del Imperio Wari.

Quintu Urqu, es un sitio estratégico, ocupado probablemente después de abandono del asentamiento de Naupallaqta, los pobladores de Quintu Urqu, debieron de mantener relaciones sociales, económicas y políticas con los asentamientos del sur (Chilcas), con el oeste (Panti), y la ceja de selva (Calicanto), con el norte con sitios ubicados en Uchuraqay e Iquicha.

Con relación a los contextos funerarios, se ha hecho una clasificación tentativa de 4 formas de patrones de entierros en cámaras, y una en chullpas. Una de las formas de construcción más conservada, aparecen construida en un abrigo rocoso. De manera general existe una secuencia de tres cámaras, la más importante se ubica en medio de cámaras laterales, generalmente estas formas arquitectónicas, poseen dinteles y umbrales de piedra pizarra tallada, muros externos enlucidos de color blanco, las partes internas son cubiertas con argamasa de barro. Estas formas de cámaras se encuentran en Marquinayuq y Uscococha. Las otras formas de cámaras, posee una sola jamba, generalmente el lado izquierdo y la otra se asocia a la roca madre del abrigo, posee umbral, pero no dintel, es construido sobre tierra excavada. Estas formas de construcción se encuentra en Marquinayuq, Pukakichka, Aweloyuq y los márgenes de los ríos Qaruapampa y Huito.

Las otras formas de cámaras funerarias, consisten en construcciones sumamente detalladas, construidas con piedras ligeramente talladas asociadas con mortero de barro en mampostería ordinaria; poseen ambas jambas, y umbrales con piedras largas y ligeramente talladas, y dintel colocadas debajo de los pisos y entrada del nicho, estas son cubiertas con argamasa de barro. La particularidad de estos nichos, es que no poseen circunferencia globular del cuerpo, son rectas, aprovechándose los abrigos rocosos como muros laterales. También no poseen tapas, son construidas hasta el techo de los abrigos, estas forman los techos. Estas formas de construcción se encuentran en Aweloyuq y Pukakichka. Las dos últimas construcciones poseen características similares, pues no poseen construcciones de piedras. Una de ellas difiere de la otra, por sus construcciones aprovechándose las paredes rocosas y arcillosas de las laderas de los abrigos, estas son talladas hasta $80 \mathrm{~cm}$ de profundidad de manera cóncava, las paredes debilitadas durante el tallado o picado son tapados con argamasa de barro, para que no queden aberturas. Estas formas de estructuras mortuorias se encuentran en Pukakakichka. La otra forma de tallado es similar, pero a diferencia del otro, son tallados en las paredes rocosas y arcillosas en las laderas que no poseen abrigos rocosos, estas generalmente son de tres grupos, o sea son distribuidos de tres en tres a una distancia de 1 metro. Algunas distancias son cortas de $50 \mathrm{~cm}$. No poseen argamasa de barro y ningún retoque. Estas formas de entierro se ubican en Aweloyuq. De lejos se observa como hoyos circulares naturales. Estas formas de entierro encontrados en los sitios arqueológicos descritos, suponen de que las sociedades prehispánicas en Tambo, mantenían el patrón de enterramiento en los abrigos rocosos, ubicadas estratégicamente en las laderas de difícil acceso. Planteamos la hipótesis de que estas formas de entierro en Tambo, se iniciaron desde el periodo Huarpa hasta el periodo Chanka.

La causa de esta larga tradición de entierros en Tambo, obedece al factor religioso (cosmovisión), a razón de que al enterrar en las laderas y abrigos rocosos, entran en contacto con el Hanan Pacha (cielo) y el Uku Pacha (inframundo), y estos se convertían en los guardianes de los cerros y la población, con un fuerte vínculo, de que se convertían en protectores. La otra posibilidad, es que estas laderas eran importantes y los pobladores prehispánicos les tenían un fuerte respeto (paqarinas), por tanto se les tenía que hacer pagapus con entierros, esto se complementa con un conjunto de rituales funerarios. 
En Tambo, también hay la presencia de chullpas mortuorias, distribuidas en el cerro de Quintu Urqu, Yupanqa y los cerros altos, del sur, este y norte, de Tambo con un fuerte vínculo del periodo Chanka.

\section{Agradecimiento}

Mi reconocimiento y gratitud a los trabajadores de la municipalidad distrital de Tambo y pobladores de las comunidades por la hospitalidad y apoyo acompañándonos a reconocer los distintos sitios arqueológicos, especialmente a Julián Medina e hijos, Jacinta Rivera e hijos, profesor Luis Quispe, Juana Cordero, Yuri Solir; familias Pérez, Ramos, Oré, Huicho, Yanasupo Quispe, Augusto Miguel, A Nemesio Carrera y Jimmy Solier, a mis abuelos Rosa Méndez y Demetrio Aquino, a todos nuestro más sincero reconocimiento.

\section{BiBLIOGRAFÍA}

AÑANCA ANCHAYHUA, William y CANCHARI HUAMANI, Miguel A.

2009 Prospección arqueológica en la microcuenca del río Churruwayqu, Chungui-La Mar. Informe del curso de Práctica Pre-Profesional (PP-Aq 542). Facultad de Ciencias Sociales, Universidad Nacional de San Cristóbal de Huamanga.

ANSCHUETZ, WILSHUSEN y SCHIECK.

2001. "Una arqueología de los paisajes: perspectivas y tendencias". En: Journal of Archaelogical Reserch. Vol. 9, N 2:152-197.

AQUINO CARRERA, Nelson

2012 Reconocimiento de sitios arqueológicos, en la cuenca alta del rio Torobamba -Tambo La Mar. Informe de práctica pre profesional. Facultad de Ciencias Sociales. Escuela de Formación Profesional de Arqueología e Historia Universidad Nacional de San Cristóbal de Huamanga. Ayacucho.

BENAVIDES CALLE, Mario

1976 Yacimientos Arqueológicos en Ayacucho. Departamento Académico de Ciencias Histórico Sociales. Ayacucho-Perú. Universidad Nacional de San Cristóbal de Huamanga.

1970 “Análisis de la Cerámica Huarpa”. Volumen.3:63-87.XXXIX, Congreso Internacional de Americanistas Lima.

BONAVIA, Duccio

1964 “Investigaciones en la Ceja de selva de Ayacucho". Arqueología y Sociedad 6: 1-65. Museo de Antropología y Etnología de la Universidad nacional Mayor de San Marcos.

1972 "La ceja de Selva: Colonizadores y avanzadas". Pueblos y culturas de la sierra central del Perú. Pp.90-99. Cerro de Pasco Corporation, Lima.

\section{CARRILLO BUSTAMANTE, Hernán}

1969 Investigaciones Arqueológicas en la Provincia de la Mar. Facultad de Ciencias Sociales. Universidad Nacional de San Cristóbal de Huamanga. Ayacucho.

1976 Catastro e inventario de monumentos arqueológicos, Ayacucho. Instituto Nacional de Cultura, Centro de Investigación y restauración de Bienes Monumentales. Lima.

1984 Inventario Arqueológico de Tambo y San Miguel Ayacucho. Facultad de Ciencias Sociales. Universidad Nacional de San Cristóbal de Huamanga., Ayacucho. 
CASTILLA RIVERA, Adán

2001 Prospección Arqueológica en la Provincia de La Mar: distrito de Tambo y Chilcas. Informe de Práctica Pre-Profesional, Escuela de Formación Profesional de Arqueología e Historia, Facultad de Ciencias Sociales. Universidad Nacional de San Cristóbal de Huamanga. Ayacucho.

CAVALCANTI, Neil Jhosew

2013 Reconocimiento y delimitación del sitio arqueológico Cedrocucho, Santa Rosa-La Mar. Informe Final del curso de Práctica Pre Profesional. Facultad de Ciencias Sociales, Universidad Nacional de San Cristóbal de Huamanga.

CORDOVA ALTAMIRANO, Luis.

2007 Prospección arqueológica en la jurisdicción del distrito de Santa Rosa en Cedrocucho-Valle del río Apurímac. Facultad de Ciencias Sociales, Universidad Nacional de san Cristóbal de Huamanga.

GLAGLIARDI R. Roberto

2013 Notas sobre una estructura de cerro Corpas. Boletín de Lima N 171: 8-12. Editorial Los Pinos Lima.

GONZALES ÑAHUI, Wendy Zulma

2014 Análisis de la cultura material del sitio arqueológico de Pampa Hermosa en el distrito de Tambo, Ayacucho. Informe de práctica Pre Profesional para optar el grado de Bachiller en Arqueología.

GONZALES CARRÉ, Enrique

1979 El estudio de los Chankas. Investigaciones 2 (2):55-76. Departamento de Ciencias Histórico-Sociales. Universidad Nacional de San Cristóbal de Huamanga.

1992 Los señoríos Chanka. Universidad Nacional de San Cristóbal de Huamanga. Instituto Andino de estudios Arqueológicos. Primera edición. Editorial. INDEA. Lima.

ISBELL, William

1970 Un pueblo Rural Ayacuchano durante el Imperio Wari. XXXIX Congreso Internacional de Americanistas, Volumen 3: 89-104. Lima.

1972

IRVING ROUSE, Benjamin

1972 Introduction to Prehistory: A Systematic Approach, New York, McGraw-Hill.

LAVALLEÉ, Daniele y JULIEN, Michele

1983 Asto: Curacazgo Prehispánico de los Andes Centrales. $1^{a}$ edición castellana. Instituto de Estudios Peruanos ediciones. Lima.

LECOQ, Patrice

2007 Resultados preliminares de las prospecciones realizadas en la región La Mar de Ayacucho, de julio a agosto de 2007. Manuscrito.

2008 Proyecto arqueológico de Choquekíraw Chanka. 
LÓPEZ A. Julio C; CERRON, Freddy; CARPIO, Mario y MORALES, María.

1996 Geología del cuadrángulo de Huanta. Hoja 26-ñ. República del Perú, sector Energía y Minas e Instituto Geológico Minero y Metalúrgico. Lima.

LUMBRERAS SALCEDO, Luis.

1959 Sobre los Chankas. Actas del II Congreso Nacional de Historia del Perú. Tomo I: 211-242. Centro de Estudios Histórico Militares del Perú. Lima.

1969 De los Pueblos, las culturas y las artes del antiguo Perú. Moncloa-Campodónico editores. Lima.

1974 Las Fundaciones de Huamanga: Hacia una Prehistoria de Ayacucho. Primera edición. Editorial Nueva Educación. Lima.

MATOS MENDIETA, Ramiro

1971 El Periodo Formativo en el valle del Mantaro. XXXIX Congreso Internacional de Americanistas, 1970. Volumen 3: 41-50. Lima.

MEDDEND, Frank y VIVANCO, Cirilo.

2005 Xama-Publicación de la unidad de Antropología del INCIHUSA, Conicet. Roberto Barcena/ editor.

LOCKARD, Gregory.

2012 Proyecto Arqueológico Melchorita PERU LNG. Impresión: Comunica2 S.A.C. Lima

PULGAR, Vidal Javier

1981 Geografía del Perú: Las Ocho Regiones Naturales del Perú. Editorial Universo. Lima.

PURIZAGA

1972 El Estado Regional en Ayacucho (Período Intermedio Tardío: 1200-1470 D.c.). Primera edición, editorial Yachaywasi, Huancayo-Perú.

TORRE YANASUPO, Wilber

2009 Prospección arqueológica en la Puna y Ceja de selva de Uchuraccay e Ikicha- Huanta. Informe Final del curso de práctica Pre Profesional (PPAQ542). Facultad de Ciencias Sociales, Universidad nacional de San Cristóbal de Huamanga.

VALDEZ CÁRDENAS, Julio

2009 Presencia de la cultura Warpa en la cuenca del rio Torobamba San Miguel, La Mar. Revista arqueológica "Warpa" № 14: 3-8". Huanta, Ayacucho.

2009 Presencia Chanka en la cuenca del río Uras, San Miguel, La Mar. Revista arqueológica "Warpa” № 14: 9-14". Huanta, Ayacucho.

VALDES, VIVANCO, CHAVEZ

1990 Asentamientos Chanka en la cuenca del Pampas-Qaracha. Gaceta Arqueológica Andina 5 (17): 17-26. Instituto Andino de estudios Arqueológicos. Lima. 
